\title{
Export Industry Policy and Reputational Comparative Advantage
}

\author{
Richard Chisik*
}

June, 2001

\begin{abstract}
$\underline{\text { Abstract }}$
Country-of-origin reputations are endogenized in this paper and it is shown that otherwise identical countries can be correctly perceived as differing in their percentage of high-quality producers. These self-fulfilling reputations determine not only the average quality of a country's exports but also the type of products in which a country specializes. Hence, the pattern of international trade can be determined by this "reputational comparative advantage." An inferior country-of-origin reputation leads to lower national welfare, therefore, several trade and industrial policies that can improve country-of-origin reputation are examined.
\end{abstract}

JEL Classification: F12, F13, J71, L15

Key Words: Country-of-Origin, Quality Reputations, Statistical Discrimination, Industrial Policy.

*Department of Economics DM-309C, Florida International University, Miami, FL, 33199; E-mail: chisikr@fiu.edu. Phone: (305) 348-3286; Fax: (305) 348-1524.

For helpful comments and discussion I am grateful to Kyle Bagwell, Chris Gust, Kiminori Matsuyama, Rob Porter, Steve Ross, Rob Simon, Chris Udry, Juuso Valimaki and seminar participants at the Universities of Connecticut, Kentucky and Texas, Northwestern, Texas A\&M and Tufts Universities, and at the Midwest Meetings in International Economics. All errors are entirely the responsibility of the author. 


\section{Introduction}

When cultivating a new export market or attempting to expand its share of an existing market, an exporter is likely to find that it has been preceded by its reputation. Absent a readily identifiable brand name, quality reputation may solely reflect the country of origin. For example, when consumers are presented with a large amount of complex product information they may use the country of origin as a heuristic in forming product impressions without considering other product attributes. ${ }^{1}$ In this paper we show that this heuristic decision making process can affect a firm's quality decision and can, therefore, become self-fulfilling. Hence, any bias that consumers have may be well-founded, however, it is only correct because firms respond rationally to it.

Colombia's garment industry provides an interesting example of a self-fulfilling unfavorable quality reputation in international trade. Although expanding at a rapid rate throughout the early 1970s Colombia's deteriorating reputation became a determining factor in the contraction of this industry. Much of this demise can be attributed to a single Colombian garment firm that took a contract (for 50,000 men's suits) that was beyond their capability. The poor-quality result so tarnished the American importer's name that other highquality importers become wary of Colombian-sewn garments. With the payoff to high-quality production reduced, Colombian garment firms then concentrated on low-quality markets, and the newly found unfavorable reputation was justified. ${ }^{2}$

In the model we construct here firms choose a product, the product's quality and an additional expenditure that may signal the unobservable product quality. The additional expenditure is less costly for high-quality firms and can, therefore, signal high quality to consumers. When noisy, this signal cannot perfectly separate product qualities, and posterior beliefs, in part, reflect country-of-origin reputations or

\footnotetext{
${ }^{1}$ See Bodenhauser and Lichtenstein (1987) and Bodenhauser and Wyer (1985). Additionally, Han and Terpstra (1988) show that products with a country-of-origin label from a developing country are rated inferior to those with an industrial country-of-origin label. Head (1993) reports that a "Made in Germany" label evokes the concepts of reliability, precision and punctuality. Bilkey and Nes (1982) find that these biases persist even when test subjects receive only country-of-origin label and no other product information.

${ }^{2}$ See Morawetz (1981) for more information on the Colombian garment industry.
} 
stereotypes. $^{3}$ As will be made clear below, firms that send a higher signal benefit more from an improvement in their country's reputation. A better stereotype, therefore, increases the desired signal level and, consequently, generates an increase in the percentage of high-quality firms. It is in this way that the reputation or stereotype becomes self-fulfilling and ex-ante identical countries can be correctly perceived as differing in their percentage of high-quality producers.

We next introduce an economy with two sectors. One sector produces more complex goods where high quality is not easily verified and is more essential to the product's performance. In particular, highquality production costs and the consumer's value for high quality goods is greater in this sector. We show that this sector becomes more profitable as the country-of-origin reputation increases. Hence, if one country's stereotype is low and the other country's stereotype is high, then the pattern of specialization and international trade can be determined solely by reputational comparative advantage. ${ }^{4}$ Finally, we show that reputational comparative advantage can overshadow a small technological comparative disadvantage in determining the pattern of international trade.

We next analyze several policy prescriptions that mitigate the adverse effects of a negative stereotype on quality selection. First, because the policymaker, like importers, does not initially observe the firm's quality choice production subsidies do not differ across qualities and can not alter the quality decision or a country's reputation. Second, high-quality production requires more physical or human capital, so that a policymaker's expenditure on education or research and development can indirectly subsidize high-quality firms. These indirect subsidies, which affect high and low quality differently, can cause more firms to choose high quality and increase a country's reputation. We show that a sufficiently large indirect subsidy

\footnotetext{
${ }^{3}$ We do not model how a reputation is earned over time, which is the more common analysis, and usage, of the word "reputation" in the economics literature. We are instead concerned with the effect of a given reputation. These reputations can be considered as stereotypes, however, we require that they are correct, or self-fulfilling, stereotypes.

${ }^{4}$ An example of the effect of reputation on a country's chosen specialty is given by Wortzel and Wortzel (1979). They show, first, that the less-complex, assembly stage in the garment industry is less profitable than the reputation-dependent, more-complex, design and marketing stage. They then provide evidence that Colombian firms, with a low-quality reputation in the U.S., import these services from abroad. For markets where they do not have a low-quality reputation, such as the Caribbean, they produce their own design and marketing services.
} 
precludes the existence of a low-reputation outcome. Third, a properly priced quality stamp (or export license) separates high and low-quality firms, and renders a bad stereotype irrelevant in the resulting equilibrium.

Armington (1969) is the first, to our knowledge, to formally recognize that consumers may distinguish seemingly identical products by their country of origin, although he did not endogenize these country-of-origin reputations nor did he recognize that they may serve as a source of comparative advantage. ${ }^{5}$ Bagwell and Staiger (1989), Bagwell (1991), Mayer (1984), Grossman and Horn (1988), and Chen (1991) examine informational barriers to entry in international trade. The latter three also introduce importers with exogenous, and pessimistic, beliefs about export quality. Because these authors recognize that exogenous beliefs are not consistent with a common prior in equilibrium, they do not fully develop the implications of pessimistic beliefs.

The paper is divided into five sections. In the next section we develop a model of self-fulfilling country-of-origin reputations. We analyze the effects of several trade policies in the third section and we introduce reputational comparative advantage in the fourth section. The fifth section contains our conclusions.

\section{Self-Fulfilling Country-of-Origin Reputations}

\section{A. A Noisy Signaling Model of an Endogenous Quality Choice.}

In the simple model we present here there are two types of countries: "A" and "B". The countries are identical in every respect except for their "A" or "B" label.

We start by analyzing the interaction of a single exporting firm and the foreign importers of its good. A firm produces its entire capacity, which is normalized to one, for export. The firm chooses the unobservable quality (at the time of purchase) of the good: $Q \in\{L, H\}$. The additional cost of high-

\footnotetext{
${ }^{5}$ Vernon (1966) notes that industrialized countries (with an established quality reputation) produce and export new products of unverifiable quality (experience goods) and developing countries produce standardized products (search goods) whose quality is easily verified. Although our explanation differs, our results correspond well with his observations. Chiang and Masson (1988) and Haucap et al (1997) also examine the relationship between country characteristics and country-of-origin quality reputation.
} 
quality production is firm specific and is directly related to the firm's type: $\theta \in \Theta=[\underline{\theta}, \bar{\theta}]$. The firm has private information about its type, which is drawn from a smooth and commonly known distribution function $F(\theta)$. The firm also has an unalterable label, $i \in\{A, B\}$, indicating country of origin. It is common knowledge that the label contains no direct information, in the sense that the distribution of types is independent of i: $F(\theta \mid i)=F(\theta)$ for all i. The label may, however, provide information about the firm's unobservable quality choice. After observing its type and label, the firm chooses the unobservable quality, $\mathrm{Q}$, and a level of additional expenditures, $\mathrm{S} \in \mathfrak{R}$, which serves to enhance the good and may serve as a signal of the firm's chosen quality.

The importers (at least two) bid for the firm's good and the firm sells to the highest bidder. By assuming that there are at least two importers who bid for the firm's product we are ensuring that price signaling by the firm is not a possibility. ${ }^{6}$ We do not make this assumption to detract from the importance of price signaling (although it may not always be an option for a small exporter in a small country), but rather to limit our analysis to a one dimensional signal. Alternatively, the arguments in this paper can be worked out for the case of a noisy price signal of product quality. (A brief example is provided in Appendix $\mathrm{B}$ of a working paper available upon request.) In the case of a tie, the firm divides the good equally among all importers offering the highest price. The importers observe the country of origin label, but do not observe the firm's type or its unobservable quality choice. Furthermore, the importers only observe a noisy realization of $S$, which is denoted as $Z=S+\varepsilon$, where $\varepsilon$ is distributed according to the smooth function $\mathrm{G}(\varepsilon)$. Hence, an importer's bid is a function $\mathrm{P}(\mathrm{Z}, \mathrm{i})$. Given its type and label a firm chooses $\{\mathrm{Q}, \mathrm{S}\}$ to maximize its expected profits, which is the difference between its conditionally expected revenue and its cost:

$$
\mathrm{E} \Pi(\theta, \mathrm{i})=\mathrm{E} \Pi(\theta, \mathrm{Q}(\theta, \mathrm{i}), \mathrm{S}(\theta, \mathrm{i}), \mathrm{i})=\mathrm{E}_{Z \mid S}[\max \mathrm{P}(\mathrm{Z}, \mathrm{i})]-\mathrm{C}(\theta, \mathrm{Q}, \mathrm{S}) .
$$

\footnotetext{
${ }^{6}$ Furthermore, the assumption that there are at least 2 importers who bid for the firm's product ensures that the firm has monopoly power. Giving the firm monopoly power yields a straightforward division of the gains from trade. Other specifications are, of course, possible, however, as long as they allow the firm to retain some of the surplus they create by producing high quality, these alternative specifications do not change our results.
} 
The timing of the game is as shown in figure 1 below.

\section{FIGURE 1 GOES APPROXIMATELY HERE.}

Our idea is the following. The firm's desired signal level, $\mathrm{S}$, is related to the country-of-origin stereotype, $\rho_{i}$, which is based on the label $i$. This relationship is captured by the expected revenue function. The relationship between the desired signal and the quality choice is given by the firm's cost function. Firms differ in their additional cost of producing high quality as captured by the firm specific type, therefore, a small change in the country-of-origin stereotype and the desired signal does not change the quality choice of all firms at the same rate. We show in this section that the key to our main result on multiple selffulfilling stereotypes is a series of monotonicity assumptions, which ensure that the received signal, $\mathrm{Z}$, is correlated with the sent signal, $\mathrm{S}$, the chosen quality, $\mathrm{Q}$, and the firm's type, $\theta$.

Consider first the cost function. To simplify our analysis we find it useful to assume that the firm's type does not directly affect their signal cost. In order to more easily discern the stereotype's effect on the measure of high-quality firms we then write the cost function as additively separable $\mathrm{C}(\theta, \mathrm{Q}, \mathrm{S})=\mathrm{I}(\theta, \mathrm{Q})+\mathrm{c}(\mathrm{Q}, \mathrm{S})$. Whereas the function $\mathrm{I}(\theta, \mathrm{Q})$ describes the relationship between the firm's type and their cost of high-quality production, the function $c(\mathrm{Q}, \mathrm{S})$ isolates the effect of the quality choice on the signal cost. The unobservable $\theta$ indexes the cost of producing high quality, an activity that is more costly for higher types: $\mathrm{I}_{\theta}(\cdot, \mathrm{H})>\mathrm{I}_{\theta}(\cdot, \mathrm{L}) \geq 0 .^{7}$ This cost may be interpreted as a setup cost, a workers' training cost or the firm's true cost of capital. These costs naturally vary across firms, and a given firm has superior information as to its true cost of quality investments. Hence, we make the assumption that the firm has private information about its specific type. We also wish to assume that firms do not select in or out of the market depending on the stereotype, otherwise an improved stereotype could paradoxically lead to an increase in the measure of low-quality firms even if some low-quality firms are switching to high-quality production. One way to ensure that the full measure of firms produce in any equilibrium is to assume that 
$\mathrm{I}(\theta, \mathrm{L})=0$ for all $\theta$ and that low-quality production is profitable under certainty and we make these assumptions. ${ }^{8}$ The additional expenditure, $\mathrm{S}$, admits a variety of interpretations. The main requirement is that it is easier for a high-quality firm to undertake the expenditure, in that a higher Q reduces the cost of S. ${ }^{9}$ These restrictions on the cost function are stated concisely as assumption 1:

$$
\mathrm{I}(\theta, \mathrm{H})>\mathrm{I}(\theta, \mathrm{L})=0 \text { for all } \theta, \mathrm{I}_{\theta}(\cdot, \mathrm{H})>0 ; \mathrm{c}_{\mathrm{S}}(\mathrm{L}, \cdot)>\mathrm{c}_{\mathrm{S}}(\mathrm{H}, \cdot)>0>\mathrm{c}_{\mathrm{SS}}(\mathrm{Q}, \cdot) . \quad \quad(\mathrm{A} 1-\mathrm{Cost})
$$

Assumption 1 captures the following idea. A firm with a lower type may choose higher quality since it lowers the cost of noisily observable signaling expenditures. The importer may thus rationally infer that a higher expenditure is associated with higher unobservable quality indicating that the firm is a low type.

We now analyze the firm's conditionally expected revenue function: $E_{Z \mid S}[\max P(Z, i)]$. The importer observes only a noisy realization of the signal, however, this information is meaningful in that

\footnotetext{
${ }^{7} \mathrm{We}$ follow the convention that a subscript refers to the partial derivative of the function with respect to the subscript: $\partial \mathrm{I}(\cdot, \mathrm{Q}) / \partial \theta \equiv \mathrm{I}_{\theta}(\cdot, \mathrm{Q})$

${ }^{8}$ Weaker restrictions can be made, howe ver, they require assumptions based on endogenously determined values. In particular, as long as the expected price for a low quality firm, which will be derived below as $\overline{\mathrm{P}}(\mathrm{L}, \mathrm{i})$ is greater than the cost for even the highest type firm, then our results will hold under the more general ordering: $\mathrm{I}(\underline{\theta}, \mathrm{H})>$ $\mathrm{I}(\underline{\theta}, \mathrm{L})$ and $\mathrm{I}_{\theta}(\cdot, \mathrm{H})>\mathrm{I}_{\theta}(\cdot, \mathrm{L}) \geq 0$. This more general ordering will be considered again in footnotes 19 and 25 below.

${ }^{9}$ A guarantee is an example of this type of expenditure. If a high-quality item has a lower repair rate, then a high level of guarantee services is cheaper for a high-quality firm to provide. (See Lutz, 1989 for more discussion of warranties as signals.) A related example is when a higher level of unobservable quality associates with a higher investment in physical or human capital. The higher level of capital allows observable quality improvements (e.g. fit, finish, etc.) or a higher-quality sample shipment to be produced at lower cost. In this way observable quality can signal unobservable quality. Product innovations are also an example of this type of signal. Producing higher unobservable quality allows a firm to develop increased technological know-how which may reduce the cost of developing incremental product innovations. For example, recent advertisements by Mercedes Benz stress their high number of patents and automobile innovations. Presumably, the benefit from anti-lock brakes is not directly related to which firm first introduced them, however, this may provide the consumer with important producer information.
} 
higher sent signals are more likely to generate higher received signals. ${ }^{10}$ Hence, the conditional density of $\mathrm{Z}$ given $S, g(Z \mid S)$, is assumed to satisfy the strict monotone-likelihood ratio property (MLRP): ${ }^{11}$

$$
S^{\prime}>S \text { and } Z^{\prime}>Z \Rightarrow g\left(Z^{\prime} \mid S^{\prime}\right) / g\left(Z^{\prime} \mid S\right)>g\left(Z \mid S^{\prime}\right) / g(Z \mid S)
$$

MLRP implies first order stochastic dominance (FOSD); therefore, the cumulative distribution function of $\mathrm{Z}$ given $\mathrm{S}, \mathrm{G}(\mathrm{Z} \mid \mathrm{S})$, satisfies FOSD. We assume, as well, that $\mathrm{g}(\mathrm{Z} \mid \mathrm{S})$ has a non-moving support so that no received signal can be ruled out for a particular product quality.

Next consider the importer's objective. Each importer has the same von Neumann-Morgenstern subutility function, $v(Q)$ which is inelastic for the firm's entire capacity. ${ }^{12}$ The importer naturally values higher quality so that $v(H)>v(L) \geq 0$. The importer's belief on the probability that a firm chose high quality, conditional on the importer's observation of the noisy signal and the country of origin can be written as $\mathrm{b}(\mathrm{Z}, \mathrm{i})=\operatorname{Pr}(\mathrm{H} \mid \mathrm{Z}, \mathrm{i})$. The importer chooses a price $\mathrm{P}$ to maximize their indirect utility function $\mathrm{U}=\gamma(\mathrm{P}) \cdot[\mathrm{u}(\mathrm{Z}, \mathrm{i})-\mathrm{P}]+\mathrm{Y}$, where $\mathrm{u}(\mathrm{Z}, \mathrm{i})$ is their expected utility from purchase, $\mathrm{Y}$ is an adequately large, exogenous, source of income, and $\gamma(\mathrm{P})$ indicates their consumption level of the good which depends on their chosen price $\mathrm{P}$ and the bid of all the other importers.

\footnotetext{
${ }^{10}$ To motivate the assumption that the firm's expenditure is not perfectly observable (i.e. it contains noise) again consider guarantees. Courts cannot view every moment of production and of product usage and, therefore, cannot perfectly identify firm or consumer moral hazard. In particular, we consider the "fine print" that is written in to any guarantee, or the natural uncertainty about a firm's willingness to uphold their guarantee, as signal noise. Presumably, these information imperfections and legal uncertainties grow in an international setting, so that, at best, a guarantee is an informative, but noisy signal of product quality. Additional sources of noisy signals include: exchange rate fluctuations that cause an importer to have imperfect information about the cost of a received signal; and elements beyond a firm's control, such as international shipping, that may cause the received signal to differ from the intended signal.

${ }^{11}$ This property is satisfied for, among others, the normal, exponential and Poisson distributions all with mean S, the log-normal with mean $\mathrm{e}^{\mathrm{S}}$, the uniform distribution, and the chi-squared distribution with non-centrality parameter S.
} 
$\mathrm{v}(\mathrm{H})>\mathrm{v}(\mathrm{L}) \geq 0 ; \mathrm{u}(\mathrm{Z}, \mathrm{i})=\mathrm{b}(\mathrm{Z}, \mathrm{i}) \cdot \mathrm{v}(\mathrm{H})+(1-\mathrm{b}(\mathrm{Z}, \mathrm{i})) \cdot \mathrm{v}(\mathrm{L}) ; \mathrm{U}=\gamma(\mathrm{P}) \cdot[\mathrm{u}(\mathrm{Z}, \mathrm{i})-\mathrm{P}]+\mathrm{Y}$

(A3-Utility)

\section{B. Description of the Equilibrium}

A sequential equilibrium is a collection of strategies and beliefs $\{S(\theta, i), Q(\theta, i), P(Z, i), b(Z, i)\}$

which satisfy the following three conditions. First, sequential rationality of the firm's strategy and of each importer's strategy requires that:

$$
\begin{aligned}
& \{\mathrm{Q}(\theta, \mathrm{i}), \mathrm{S}(\theta, \mathrm{i})\} \in \operatorname{argmax}_{\mathrm{Q}, \mathrm{s}}\left\{\mathrm{E}_{\mathrm{Z} \mid \mathrm{S}}[\mathrm{P}(\mathrm{Z}, \mathrm{i})]-\mathrm{C}\left(\theta, \mathrm{Q}_{\mathrm{j}}, \mathrm{S}_{\mathrm{j}}\right)\right\} \\
& \mathrm{P}(\mathrm{Z}, \mathrm{i}) \in \operatorname{argmax}_{\mathrm{P}}=\gamma(\mathrm{P}) \cdot[\mathrm{u}(\mathrm{Z}, \mathrm{i})-\mathrm{P}]+\mathrm{Y}
\end{aligned}
$$

(E1-Firm),

(E1-Importer).

Second, because the signal is noisy, with a non-moving support, all actions are on the equilibrium path; therefore, no refinements are needed to restrict attention to reasonable equilibria and, for all $\mathrm{Z}$, equilibrium beliefs are derived by Bayes' rule:

$$
\mathrm{b}(\mathrm{Z}, \mathrm{i})=\operatorname{Pr}(\mathrm{H} \mid \mathrm{Z}, \mathrm{i})=\frac{1}{1+\operatorname{LR}(\mathrm{Z}) \frac{1-\rho_{\mathrm{i}}}{\rho_{\mathrm{i}}}}
$$

The likelihood ratio $\mathrm{LR}(\mathrm{Z})=\mathrm{g}(\mathrm{Z} \mid \mathrm{L}) / \mathrm{g}(\mathrm{Z} \mid \mathrm{H})$, where $\mathrm{g}(\mathrm{Z} \mid \mathrm{Q})$ is the probability density of $\mathrm{Z}$ given $\mathrm{Q}$ and $\rho_{\mathrm{i}}=$ $\operatorname{Pr}(\mathrm{H} \mid \mathrm{i})$ is the importer's conjecture that a firm in country i will choose high quality. (i.e. $\rho_{\mathrm{i}}$ is the countryof-origin reputation or stereotype.) Although $\rho_{\mathrm{i}}$ is presently taken as a parameter the third equilibrium condition states that it must be correct in equilibrium and consistent with the common prior over the distribution of types. Hence, $\rho_{\mathrm{i}}$ is to be endogenized.

The third equilibrium condition can be more intuitively expressed after the statement of the following lemma.

\footnotetext{
${ }^{12}$ We have implicitly assumed that the importer receives no utility from the intended or realized signal level. In a working paper we consider the more general case, $\mathrm{v}(\mathrm{Q}, \mathrm{Z})$, and also analyze a non-dissipative signal, such as guarantees and some product enhancements, whereby the importer also prefers a higher signal: $v_{Z}(Q, \cdot)>0$. We show there that our results hold as long as the marginal utility of $\mathrm{Z}$ is no lower in a high-quality good: $\mathrm{v}_{\mathrm{Z}}(\mathrm{H}, \cdot) \geq$ $\mathrm{v}_{\mathrm{Z}}(\mathrm{L}, \cdot)$. This ordering preserves the monotonicity between the firm's type and the realized signal level. Interestingly, a greater warranty may be appreciated more in a lower quality good so that the above cross-partial derivative does not hold. Our results then require additional conditions to obtain in this case. With some slight
} 
Lemma 1: Assume $(A 1, A 3)$ are satisfied. Then $\mathrm{P}(\mathrm{Z}, \mathrm{i})=\mathrm{u}(\mathrm{Z}, \mathrm{i})$, for all importers are the unique equilibrium prices.

All proofs are contained in the appendix.

Lemma 1 indicates that Bertrand competition among the importers results in each bidding a price equal to their expected value for the good. It suggests that our model can be interpreted as describing a firm in a small country (that cannot affect world price) and that, therefore, can sell its entire output at the going world price - for a good of that perceived quality. ${ }^{13}$

Using Lemma 1, the firm's conditionally expected revenue can be written as

$$
\overline{\mathrm{P}}(\mathrm{S}, \mathrm{i})=\mathrm{E}_{\mathrm{Z} \mid \mathrm{S}}[\max \mathrm{P}(\mathrm{Z}, \mathrm{i})]=\int_{Z} \mathrm{u}(\mathrm{Z}, \mathrm{i}) \mathrm{dG}(\mathrm{Z} \mid \mathrm{S}) .
$$

The following notational considerations will prove useful. First, note that $\mathrm{S}$ is only dependent on $\theta$ through the firm's choice of $\mathrm{Q}(\theta, \mathrm{i})$, and $\mathrm{Q}$ and $\mathrm{S}$ are only dependent on the label, i, through the importer's belief, therefore, we can write $\mathrm{S}\left(\mathrm{Q}, \rho_{\mathrm{i}}\right)=\mathrm{S}\left(\mathrm{Q}\left(\theta, \rho_{\mathrm{i}}\right), \rho_{\mathrm{i}}\right)=\mathrm{S}(\theta, \mathrm{i})=\operatorname{argmax}_{\mathrm{S}} \mathrm{E} \Pi\left(\theta, \mathrm{Q}, \mathrm{S}, \rho_{\mathrm{i}}\right)$. Hence, $\mathrm{S}(\mathrm{H}$, $\left.\rho_{i}\right)$ is the amount of expenditure chosen by a high-quality firm when the stereotype is $\rho_{i}$ and $S\left(L, \rho_{i}\right)$ is defined similarly. Remembering that the low-quality firm's profit is the same for all $\theta$, the marginal firm, $\theta^{\mathrm{H}}$, is defined as the solution to:

$$
\text { EП[ } \left.\theta^{\mathrm{H}}, \mathrm{H}, \mathrm{S}\left(\mathrm{H}, \rho_{\mathrm{i}}\right), \rho_{\mathrm{i}}\right]-\mathrm{E}\left[\boldsymbol{\theta}, \mathrm{L}, \mathrm{S}\left(\mathrm{L}, \rho_{\mathrm{i}}\right), \rho_{\mathrm{i}}\right]=0 .
$$

Hence, $\theta^{\mathrm{H}}$ is the type of the firm that is indifferent between high and low quality and is, therefore, the highest type choosing high quality. Thus, $\mathrm{F}\left(\theta^{\mathrm{H}}\right)$ is the empirical measure of firms choosing high quality. The third equilibrium condition, consistency with a common prior distribution, then requires:

$$
\rho_{\mathrm{i}}=\operatorname{Pr}(\mathrm{Q}=\mathrm{H} \mid \mathrm{i})=\operatorname{Pr}\left(\mathrm{E} \Pi\left[\theta, \mathrm{H}, \mathrm{S}\left(\mathrm{H}, \rho_{\mathrm{i}}\right), \rho_{\mathrm{i}}\right] \geq \mathrm{E} \Pi\left[\theta, \mathrm{L}, \mathrm{S}\left(\mathrm{L}, \rho_{\mathrm{i}}\right), \rho_{\mathrm{i}}\right]\right)=
$$

additional complications we can also consider the case whereby the importer's sub-utility is a function of the intended signal $(\mathrm{S})$ as opposed to realized signal $(\mathrm{Z})$. 


$$
\begin{aligned}
& \operatorname{Pr}\left(\mathrm{E} \Pi\left[\theta, \mathrm{H}, \mathrm{S}\left(\mathrm{H}, \rho_{\mathrm{i}}\right), \rho_{\mathrm{i}}\right] \geq \mathrm{E} \Pi\left[\theta^{\mathrm{H}}, \mathrm{H}, \mathrm{S}\left(\mathrm{H}, \rho_{\mathrm{i}}\right), \rho_{\mathrm{i}}\right]\right)= \\
& \operatorname{Pr}\left[\mathrm{I}(\theta, \mathrm{H}) \leq \mathrm{I}\left(\theta^{\mathrm{H}}\left(\rho_{\mathrm{i}}\right), \mathrm{H}\right)\right]=\operatorname{Pr}\left(\theta \leq \theta^{\mathrm{H}}\left(\rho_{\mathrm{i}}\right)\right)=\mathrm{F}\left(\theta^{\mathrm{H}}\left(\rho_{\mathrm{i}}\right)\right),
\end{aligned}
$$

(E3-Consistency)

so that the importer's conjecture induces that same measure of firms to choose high quality. Consistency is essentially a fixed point argument.

\section{Self-fulfilling Conjectures}

To see how multiple equilibria may arise we first establish the effect of country-of-origin stereotypes, $\rho_{\mathrm{i}}$, on signals, $\mathrm{S}$, quality choice, $\mathrm{Q}$, and on the marginal firm, $\theta^{\mathrm{H}}$.

Proposition 1: If A1-A3 are satisfied, then for $\rho_{\mathrm{i}}$ near zero, $\theta^{\mathrm{H}}$ is strictly increasing in $\rho_{\mathrm{i}}$, and, as $\rho_{\mathrm{i}}$ approaches one, $\theta^{\mathrm{H}}$ is strictly decreasing in $\rho_{\mathrm{i}}$.

The intuition behind Proposition 1 is as follows. For the most pessimistic stereotypes $\left(\rho_{i}=0\right)$ any realized signal $(\mathrm{Z})$, no matter how high, is attributed to a low quality firm and has no effect on the importer's belief. Hence, no firm chooses high-quality in this case and $\rho_{i}=0$ must be an equilibrium. ${ }^{14}$ Increasing $\rho_{\mathrm{i}}$, from this most pessimistic level has a positive effect on the importer's belief and, therefore, raises the exporter's desired expenditure $(\mathrm{S})$ which, in turn, increases the benefit of becoming a high-quality firm (so as to lower the cost of the additional expenditure) and, therefore, increases the measure of highquality firms so that $\theta^{\mathrm{H}}\left(\rho_{\mathrm{i}}\right)$ is increasing in $\rho_{\mathrm{i}}$. For a very high conjecture $\left(\rho_{\mathrm{i}}\right.$ near 1$)$ importers believe that the firm is of high quality, irrespective of the observed signal realization. The firm, therefore, has less desire for a high signal which reduces the firm's signal-cost saving rationale for becoming high quality. Hence, very high conjectures induce a reduction in the measure of high quality firms so that $\theta^{\mathrm{H}}\left(\rho_{\mathrm{i}}\right)$ is decreasing in $\rho_{\mathrm{i}}$ in this range and these overly optimistic conjectures cannot be correct in equilibrium.

\footnotetext{
${ }^{13}$ The garment industry provides a useful analogy. Much of the sewing of garments is done in small shops in newly industrializing countries. These shops often contract to sell their entire output to one or two importers for a set period of time.

${ }^{14}$ In the case of a non-dissipative signal, whereby $\mathrm{v}_{\mathrm{Z}}(\mathrm{Q}, \cdot)>0$, the signal may be so valuable to consumers that even under the most pessimistic stereotype some firms become high quality to save on the signaling expenditure and, therefore, $\rho_{\mathrm{i}}=0$ may not be an equilibrium. A similar result obtains if $\mathrm{I}(\underline{\theta}, \mathrm{H}) \leq 0$.
} 


\section{FIGURE 2 GOES APPROXIMATELY HERE}

The relationship between $\rho_{\mathrm{i}}$ and $\theta^{\mathrm{H}}\left(\rho_{\mathrm{i}}\right)$ suggested by Proposition 1 is illustrated in Figure 2 .

Proposition 1, however, only ensures that $\theta^{\mathrm{H}}\left(\rho_{\mathrm{i}}\right)$ is at first increasing and then eventually decreasing in $\rho_{\mathrm{i}}$. It does not ensure that multiple equilibria exist. For example, if $\mathrm{I}(\theta, \mathrm{H})$ is very high for all exporter types, then no exporter chooses high quality and $\rho_{\mathrm{i}}=0$ is the only equilibrium. For multiple equilibria to arise it is, therefore, necessary to place the following restriction on the variation in $\mathrm{I}(\theta, \mathrm{H})$ :

There exists a $\rho^{\prime}$ and a $\rho^{\prime \prime}$ such that $0<\rho^{\prime}<\rho^{\prime \prime}<1, \rho^{\prime}=F\left(\theta^{\prime}\right), \rho^{\prime \prime}=F\left(\theta^{\prime \prime}\right)$, and

$$
\mathrm{I}\left(\theta^{\mathrm{H}}\left(\rho_{\mathrm{i}}^{\prime}\right), \mathrm{H}\right)<\mathrm{I}\left(\theta^{\prime}, \mathrm{H}\right)<\mathrm{I}\left(\theta^{\prime \prime}, \mathrm{H}\right)<\mathrm{I}\left(\theta^{\mathrm{H}}\left(\rho_{\mathrm{i}}^{\prime \prime}\right), \mathrm{H}\right)
$$

(A4-Variation)

Assumption 4 indicates that there exists a range of values of $\rho_{i}$ and $\theta$ such that expected revenue of a highquality firm is increasing faster in $\rho_{\mathrm{i}}$ than the cost of becoming high-quality is increasing in $\theta$. To see this, note that manipulation of (A4) yields: $\overline{\mathrm{P}}\left(\mathrm{S}, \rho_{\mathrm{i}}{ }^{\prime \prime}\right)-\overline{\mathrm{P}}\left(\mathrm{S}, \rho_{\mathrm{i}}{ }^{\prime}\right)>\mathrm{I}\left(\theta^{\prime \prime}, \mathrm{H}\right)-\mathrm{I}\left(\theta^{\prime}, \mathrm{H}\right)$. Put another way, (A4) indicates that multiple reputational equilibria are more likely to exist when firms are similar, so that the variation in their high-quality cost is small. Similarly, these multiple equilibria are more likely to arise for products in which a high-quality reputation has a larger positive effect on firm revenue.

Proposition 2: Under $(A 1-A 4)$ there generically exists at least three, and an odd number of, equilibria. A more favorable conjecture is associated with a more favorable equilibrium.

By proving that there exists at least three equilibria (and at least two stable equilibria) we establish the existence of at least two stable self-fulfilling conjectures. ${ }^{15}$ That the number of equilibria is odd is

\footnotetext{
${ }^{15}$ Using the natural stability condition, $\mathrm{d}\left(\mathrm{F}\left(\theta^{\mathrm{H}}\left(\rho_{\mathrm{i}}\right)\right)-\rho_{\mathrm{i}}\right) / \mathrm{d} \rho_{\mathrm{i}}<0$ we note that the most unfavorable and all equilibria where $\mathrm{F}\left(\theta^{\mathrm{H}}\left(\rho_{\mathrm{i}}\right)\right)$ crosses the $45^{\circ}$ line from above are stable with respect to a small perturbation of the importers' beliefs, therefore, there are a minimum of 2 stable equilibria.
} 
certainly not unique to our framework and, in fact, is to be expected. ${ }^{16}$ The are, however, three novel items about self-fulfilling stereotypes here. First, they are shown to arise in the case of export quality (a point that has not been previously recognized in the literature). Second, the country-of-origin label serves as a coordinating device. That is, although there are multiple equilibria, the country-of-origin label is a natural focal point. Hence, for each country there is an unique equilibrium prediction. The emphasis of the paper is not the existence of multiple equilibria, however, an important finding is that the country-of-origin label that generates them can also become a coordinating device or focal point.

Third, our approach to reputation and equilibrium selection based on conventions is related to Arrow's (1974) model of statistical discrimination in labor markets and it augments this line of research as follows. A natural response to Arrow's model (or to the more recent adaptation by Coate and Loury, 1993) is to suggest that the discriminated against group should signal their quality (or ability) by choosing an additional action that is correlated with their hidden type and can, therefore, reveal their true (but unobservable) quality. The additional expenditure, $\mathrm{S}$, is this type of signal. We show in a working paper that without any signal noise there is an unique separating sequential equilibrium that satisfies a typical dominance refinement. On the other hand, we see here that even with an arbitrarily small amount of signal noise it is the signal itself that generates the statistical discrimination and, therefore, it cannot serve as a possible solution. ${ }^{17}$ As real world signals are generally not perfectly observed we believe that this point has important implications beyond our chosen application.

\footnotetext{
${ }^{16}$ Although there are multiple equilibria there are no non-degenerate mixed strategy equilibrium. A mixed strategy requires a player to be indifferent between more than one pure strategy. Because there is a continuum of types, because the strategy space is continuous and because of our monotonicity assumptions there is a unique best response for each possible conjecture, therefore, no mixed strategy equilibrium exists in the present case. Our application is related to a general case for which one can show that if, for all players, the strategy space is a convex set and the payoff functions are strictly quasiconcave, then any mixed strategy equilibrium must be degenerate. ${ }^{17}$ A slightly related idea is introduced in Bagwell (1995) who shows that an arbitrarily small amount of noise in the first mover's action can nullify their first mover advantage. One of Maggi's (1999) extensions is a relaxation of the non-moving support assumption.
} 
We now consider the welfare properties of the equilibrium set. ${ }^{18}$

Proposition 3: Assume (A1-A4). Equilibria where importers have a more favorable conjecture are interim Pareto superior to equilibria that are induced from a less favorable conjecture. A high-quality firm always benefits more than a low-quality firm when the equilibrium conjecture increases.

The intuition behind Proposition 3 is as follows. All firms benefit from a more favorable equilibrium because it increases their expected revenue. Because importers pay their expected surplus for the good, they are indifferent over the set of equilibria. The last claim in Proposition 3 is the most interesting. For a higher conjecture to be correct in equilibrium it has to induce some low-quality firms, that were formally at the margin, to become high-quality firms. Hence, high-quality firm profits must increase faster than low-quality firm profits in the move to a more favorable equilibrium.

\section{Trade and Industrial Policy}

When analyzing the welfare consequences of trade and industrial policy, we consider a simple national welfare function that is commonly utilized in partial equilibrium analyses of trade policy when all production is earmarked for export. In particular, welfare is the sum of the firm's profits plus any government revenue, $\mathrm{R}$, (which may be negative): $\mathrm{W}(\theta, \mathrm{i}, \mathrm{R})=\sum_{\mathrm{j}} \mathrm{E} \Pi\left(\theta_{\mathrm{j}}, \mathrm{i}\right)+\mathrm{R}$. We extend our model by considering several export firms, which are indexed by $\mathrm{j}$. We also introduce a policymaker who has the authority to administer trade and industrial policies and to raise and distribute government revenues in a lump sum fashion. The policymaker has no more information than do consumers: she knows the distribution of types and the equilibrium stereotype. The policymaker announces the policy after each firm learns its type, but before any production decisions are made. Also before any production decisions are made the firm may publicly respond to the policy, if applicable. After this stage, the timing of the game proceeds as before. Finally, after a product is consumed its unobservable quality is revealed to the

\footnotetext{
${ }^{18}$ Because each player knows their own type, but the importer doesn't, interim welfare comparisons are the natural choice in this situation. See Holmstrom and Myerson (1983) for further discussion of the appropriate welfare
} 
policymaker who may then collect or issue payments in accordance with the policy, if applicable. The timing in this section is shown below in Figure 3.

\section{FIGURE 3 GOES APPROXIMATELY HERE.}

\section{A. Direct and Indirect Subsidies}

Consider first a direct subsidy that lowers production costs. In our framework all firms are identically sized. Although this is a simplifying assumption, it captures the idea that there is no expected a priori relationship between firm size and quality choice. Put another way, because high- and low-quality firms produce the same quantity the policymaker ends up giving each firm the same subsidy irrespective of their chosen quality. Hence, by affecting all firms equally a production subsidy does not change the incentives for producing high quality and cannot improve a country's unfavorable reputation. Furthermore, using the national welfare function, it is straightforward to see that a production subsidy merely redistributes wealth from inhabitants to firms and has no effect on national welfare. ${ }^{19}$

To effect a change in a country's reputation, a subsidy must affect each quality differently. Because, the cost of unobservable quality is greater for higher-quality firms, $I(\theta, H)>I(\theta, L)$, this may be accomplished by a subsidy to the cost of unobservable quality, $\mathrm{I}(\theta, \mathrm{Q})$. The motivation given above (in section II.a.) for the greater cost of producing high unobservable quality suggests that high-quality firms make a greater investment in human or physical capital. High-quality firms, therefore, benefit more from a reduction in the cost of obtaining this capital. For example, improving the technical competence of the labor force reduces a firm's cost of adding human capital. Similarly, the policymaker could support technical and scientific research, and thereby reduce this high-quality capital cost.

comparison in games of incomplete information. 
Reducing the cost of this capital, here, lowers the function $\mathrm{I}(\theta, \mathrm{H})$ without requiring a direct subsidy on capital investments. For example, a national subsidy of $\sigma^{\mathrm{K}}$ is divided among the endogenously determined $\mathrm{F}\left(\theta^{\mathrm{H \sigma}}\left(\rho_{\mathrm{i}}\right)\right)$ high-quality firms, where $\theta^{\mathrm{H \sigma}}\left(\rho_{\mathrm{i}}\right)$ is the marginal firm when the policy $\sigma$ is instituted.

Each high-quality firm, therefore receives a subsidy of $\sigma_{j}^{\mathrm{K}}=\sigma^{\mathrm{K}} / \mathrm{F}\left(\theta^{\mathrm{H \sigma}}\left(\rho_{\mathrm{i}}\right)\right)$, so that the firm-specific cost of producing high unobservable quality becomes $I^{\sigma}\left(\theta_{j}, H\right)=I\left(\theta_{j}, H\right)-\sigma_{j}^{K}$.

\section{FIGURE 4 GOES APPROXIMATELY HERE}

When starting from a stable equilibrium, the national subsidy produces a more favorable equilibrium because reducing the cost of high-quality production is equivalent to a perceived downward shift in the distribution $F(\theta)$. The pre-subsidy distribution first-order stochastically dominates the post-subsidy perceived distribution, and this shift necessitates an increase in the equilibrium conjecture. The effect of a subsidy is illustrated in Figure 4. We see there that a small subsidy increases the measure of high-quality firms (and national reputation) in all stable equilibria. Therefore, as also shown in Figure 4, there exists a larger subsidy which eradicates all but the most favorable equilibrium beliefs. Because the subsidy is a transfer from taxpayers to the policymaker to the firms it has no direct effect on welfare. Its indirect effect, however, increases welfare as in Proposition $3 .^{20}$ Proposition 4 formalizes this discussion.

Proposition 4: An indirect subsidy of $\sigma^{\mathrm{K}}$ to lower the cost of acquiring human or physical capital

${ }^{19}$ Here, all low-quality exporters have the same profit. If this assumption we re relaxed so that $\mathrm{I}_{\theta}(\cdot, \mathrm{L})>0$, then a production subsidy could have a negative effect on the importer's prior. To see this, suppose that $\theta^{\mathrm{H}}$ is the highest $\theta$ choosing high quality and $\theta^{\mathrm{L}} \in\left(\theta^{\mathrm{H}}, \bar{\theta}\right)$ is the highest $\theta$ choosing low quality so that exporters with $\theta \in\left(\theta^{\mathrm{L}}, \bar{\theta}\right)$ choose not to produce in an unfavorable equilibrium with no government policy. A production subsidy affects the profits of both quality choices equally and has no effect on $\theta^{\mathrm{H}}$; however, by increasing the low-quality exporter's profits, the subsidy allows some additional low-quality firms (with $\theta>\theta^{\mathrm{L}}$ ) to earn positive profits. As in Grossman and Horn (1988), the production subsidy promotes adverse selection of marginal low-quality producers into the industry without alleviating the moral hazard in quality choice, thereby lowering the importer's prior beliefs.

${ }^{20}$ As long as the subsidy reduces high-quality costs by more than it reduces low-quality costs it does not change our result if the subsidy is given equally to all firms. Of greater concern is the means of raising the funds for this subsidy. If there is a positive cost involved in administering the necessary tax and dissemination of the subsidy, then public funds have a greater social cost than private funds and the subsidy is not merely a transfer. In this case a small subsidy can increase reputation but may not increase welfare. On the other hand, by eradicating bad reputations and generating a large jump in equilibrium beliefs, a larger subsidy is more likely to increase welfare. 
strictly increases the measure of high-quality firms in all stable equilibrium where $\rho_{\mathrm{i}} \neq 0$ and improves welfare for the exporting country.

It is of some interest to consider the information content of this subsidy. It is reasonable to expect that education attainment levels as well as technological sophistication are observable to foreign importers. Furthermore, foreigners may believe that these observables are correlated with high quality. ${ }^{21}$ The key point, here, is that these observables lower the cost of producing high quality more than they lower the cost of producing low quality so that these beliefs are, in fact, correct.

\section{B. Quality Rewards, Quality Stamps and Export Licenses.}

In this section we consider the enforcement capability of the policymaker in helping a high-quality firm separate itself from a low-quality firm and, therefore, from a low country-of-origin reputation. It is also interesting to consider as well a non-government entity such as a trade association that can perform the same role as the policy maker. We are interested in a reward to high quality firms and in a punishment to firms that misrepresent their quality choice.

Consider first a reward to firms that have produced high-quality. By increasing their profit it could increase the measure of high-quality firms. A potential time inconsistency problem exists, however, in administering this reward policy. The reward's effect on production and the offered price occurs before the policymaker bestows the reward, therefore, there is no reason for the policymaker to follow through on her claim. Recognizing this potential time inconsistency firms may not alter their quality decision and consumers may not alter their beliefs. Furthermore, this costless claim (of a high-quality reward) is presumably less likely to be believed when it come from countries with an unfavorable reputation for

\footnotetext{
${ }^{21}$ Although importers may have these beliefs, they may have other beliefs. We do not consider government policies that may be effective because they may alter importer's beliefs. An example of the type of policy that we don't want to consider is that employed by Usa, Japan when their country suffered from an unfavorable reputation. Their policy was to stamp on goods produced there that they were "Made in U.S.A."
} 
product quality or for policymaker credibility. A successful reward-subsidy must, therefore, involve more than a costless claim at the time when quality is chosen.

Consider second, a guarantee that is backed by the policymaker or by an outside agency such as a trade association. It may avoid some of the above mentioned problems with consumer perceptions of firm compliance, still, the possibility of consumer and firm moral hazard renders a perfect guarantee as prohibitively costly to an outside agency that has no enforcement power over firm quality.

To overcome these two above mentioned difficulties we now consider an optional tax that is rebated only to firms that produce high quality. When administered by a policymaker this tax may be interpreted as an export license. Whether administered by the policymaker or a credible outside agency this tax can serve as a high-quality stamp. If the stamp (or export license) price is chosen correctly only highquality firms will purchase the stamp. The stamp, therefore, effectively separates high and low quality and it renders country-of-origin reputation irrelevant in determining the equilibrium. Although it effectively guarantees the firm's product, this stamp is immune to consumer moral hazard. Furthermore, because it is a rebate, it is costless to provide the reward to firms, however, for firms that purchase the high-quality stamp it is certainly not a costless claim. ${ }^{22}$

Proposition 5: The following Bayesian, incentive-compatible, voluntary-participation mechanism perfectly separates high and low-quality firms, eradicates unfavorable equilibrium conjectures and satisfies budget balance.

After learning their type, but before production decisions are made, firms can purchase a highquality stamp at a price of:

$$
\tau^{R}=\bar{P}(S(L, 1), 1)-\bar{P}(S(L, 0), 0)+k
$$

\footnotetext{
${ }^{22}$ Because this high-quality stamp can effectively separate low- and high-quality firms, some information sets are reached with zero probability. Bayes' rule is not applicable at these information sets and quite unreasonable beliefs can become correct in equilibrium. These unreasonable equilibria are supported by beliefs whereby some firm played a strictly dominated strategy. We choose to ignore such equilibria and impose a dominance refinement on the set of equilibria. This belief refinement states that at all information sets the posterior beliefs ascribe zero probability to the event that a firm played a strictly dominated strategy. It is stated formally in the Appendix.
} 
where $\mathrm{k}$ is an arbitrarily small positive constant. The stamp price is refunded if the firm produces high quality and nothing is repaid otherwise.

Because high-quality firms receive the rebate they willingly pay the tax if it has a positive effect on beliefs. In the equilibrium induced by the $\tau^{\mathrm{R}}$ policy the expected revenue for all low-quality firms without a stamp is $\overline{\mathrm{P}}(\mathrm{S}(\mathrm{L}, 0), 0)$. Alternatively, a low-quality firm that purchases the high-quality stamp but does not receive the rebate has expected revenue of $\bar{P}(S(L, 1), 1)-\tau^{R}=\bar{P}(S(L, 0), 0)-k$. Hence, only highquality firms purchase the stamp and the importers' beliefs must recognize this.

An example of a related export license was utilized by Japan. When they suffered from a lowquality reputation, Japan stamped some goods with a JIS logo, which was designed to assure foreign consumers (due to the non-Japanese characters) that the product met a minimum quality standard. It need not be administered by a policymaker. For example, it is regional trade associations that sell the high-quality stamps to European wine producers. These stamps assure consumers that the regional trade association will make a random sample of the wineries product and that the winery will forfeit a bond and lose further stamp purchasing privileges if the quality is below a certain level. ${ }^{23}$

Note that we are implicitly assuming that the policymaker or trade association learns of the product's quality by taking a small sample of each of the exported goods. Alternatively, the product quality may be revealed through importer testimonials. Because the policy in Proposition 6 does not make any payments to importers of a low quality product, the importers have no incentive to misrepresent their experience with the good, therefore, a truthful revelation equilibrium would exist. Alternatively, a trade association may take a random sample of the export goods. In this case the stamp price must be adjusted for the probability of being sampled. Although this addition slightly complicates the analysis it in no way alters our results.

\footnotetext{
${ }^{23}$ California wineries also have their quality verified by a regional association, however, Chilean agriculture saw an increase in their quality reputation as a result of a nationally administered policy.
} 
A potential problem with this program is the policymaker's (or trade association's) credibility. If firms do not believe that the policymaker will pay the rebate, the incentive for high-quality production is reduced. More importantly, if consumers believe that the tax will be rebated regardless of quality, they must reevaluate their beliefs. Finally, note that a low-quality firm's profits are lower in the program. Whereas the $\sigma^{\mathrm{K}}$ subsidy increases the profits of low-quality firms by increasing the equilibrium beliefs, the $\tau^{\mathrm{R}}$ policy perfectly reveals low-quality producers and decreases their profits. It is straightforward to verify that if the pre-policy belief is highly unfavorable, or if most firms choose high quality when their choice is known with certainty, then this policy increases the exporting country's welfare. ${ }^{24,25}$

\section{Reputational Comparative Advantage and the Pattern of International Trade}

We now show that the pattern of trade between two countries may be determined by reputation rather than technological or factor endowment differences. In addition, reputational comparative advantage may, under certain conditions, take precedence over technological comparative advantage.

We wish to maintain the more tractable partial-equilibrium intuition of the previous sections, however, we do wish to consider the possibility of trade between two countries. We extend our model as follows. There are $\mathrm{N}_{\mathrm{i}}$ firms, indexed by $\mathrm{j}$, in country $\mathrm{i}$. The manufactured goods are now produced for consumption by the $\eta_{i}$ identical agents in each country. These "consumers" take the place of the importers in the previous sections. The agents' preferences can be represented by the utility function described in A3 and the agents' income is now endogenized as their equal share of the firm's profits and the wage (normalized to one) that is paid to their one endowed unit of labor. Their identical indirect utility functions can be represented as:

\footnotetext{
${ }^{24}$ In Bagwell and Staiger (1989), a first-period tax followed by a second-period rebate for high quality always improves welfare. A low first-period price that signals high quality is a transfer to foreigners and there is a possibility of no exports in a pooling equilibrium.

${ }^{25}$ If low-quality exporters also pay a positive investment cost then this policy also precludes entry of high cost, low-quality exporters. Because adverse selection is not a problem here, the lost entry means a loss of profit. On the other hand, by reducing the number of potential low-quality producers, the export license can effectively increase national reputation so that the export license may be discontinued in the future.
} 
$\mathrm{V}(\mathrm{Z}, \mathrm{P}, \theta, \mathrm{i}, \eta)=\sum_{\mathrm{i}} \sum_{\mathrm{j}} \gamma_{\mathrm{ij}}\left(\mathrm{P}_{\mathrm{ij}}\right) \cdot\left[\mathrm{u}\left(\mathrm{Z}_{\mathrm{j}}, \mathrm{i}\right)-\mathrm{P}\left(\mathrm{Z}_{\mathrm{j}}, \mathrm{i}\right)\right]+\sum_{\mathrm{j}} \mathrm{E \Pi}\left(\theta_{\mathrm{j}}, \mathrm{i}\right) / \eta_{\mathrm{i}}+1=\sum_{\mathrm{j}} \mathrm{E \Pi}\left(\theta_{\mathrm{j}}, \mathrm{i}\right) / \eta_{\mathrm{i}}+1$

From Lemma 1 all consumers bid $u\left(Z_{j}, i\right)=P\left(Z_{j}, i\right)$. If one consumer bids less than $u\left(Z_{j}, i\right)$, then for that consumer $\gamma_{i j}=0$. This observation yields the second equality in equation (3). ${ }^{26}$

We now explicitly consider two countries $i \in\{A, B\}$ and two manufacturing sectors, $S \in\{\alpha, \beta\}$.

Firms can produce in either sector and choose their sector after seeing their type and country-of-origin label, but before any other production decisions are made. Within a sector, each firm produces a differentiated version of that sector's good. The sectors differ in their production cost, and consumer value, for high quality products. To be concrete, we assume that the $\alpha$ sector constitutes more sophisticated products than the $\beta$ sector. A related interpretation of the difference between sectors is that the $\beta$ sector comprises assembly of simple electronic items or ready-to-wear apparel and the $\alpha$ sector, on the other hand, consists of the design and marketing of these $\beta$ sector goods.

In particular, we choose a unit of output so that low-quality utility for each sector is the same. Our assumption then implies that high-quality utility is greater in sector $\alpha$. Similarly, low-quality costs are the same in both sectors, however, high-quality production is more expensive in sector $\alpha$.

$$
\begin{aligned}
& \mathrm{v}(\alpha, \mathrm{H})>\mathrm{v}(\beta, \mathrm{H})>\mathrm{v}(\alpha, \mathrm{L})=\mathrm{v}(\beta, \mathrm{L}) \\
& \mathrm{I}(\theta, \alpha, \mathrm{H})>\mathrm{I}(\theta, \beta, \mathrm{H})>\mathrm{I}(\theta, \alpha, \mathrm{L})=\mathrm{I}(\theta, \beta, \mathrm{L})=0 .
\end{aligned}
$$

In the appendix we show that as $\rho_{\mathrm{i}}$ increases, $\alpha$ sector goods become more profitable than $\beta$ sector goods. Hence, sector $\alpha$ products are more reputation intensive. The economic intuition behind this result is that a larger $\rho_{\mathrm{i}}$ attaches greater posterior probability to high quality, which is more valuable for sector $\alpha$. Hence, there is a single-crossing-property between sectors and conjectures:

\footnotetext{
${ }^{26}$ We show in Appendix $\mathrm{C}$ of a working paper that by introducing a numeraire good, interpreting each $\theta_{\mathrm{ij}}$ as a specific factor, and allowing labor mobility between the $\mathrm{N}_{\mathrm{i}}$ firms and the numeraire sector, equilibrium for country "i" is then described by equations (E1 - E3), (3) and a resource constraint.
} 
$\partial \mathrm{E} \Pi(\theta, \alpha, \mathrm{Q}, \mathrm{S}, \cdot) / \partial \rho>\partial \mathrm{E} \Pi(\theta, \beta, \mathrm{Q}, \mathrm{S}, \cdot) / \partial \rho$. Furthermore, there exists a $\rho^{*}$ such that if $\rho_{\mathrm{i}} \leq \rho^{*}$, then high-quality $\beta$ sector goods are more profitable (because of the greater high-quality cost in sector $\alpha$ ); and if $\rho_{\mathrm{i}}>\rho^{*}$, then high-quality $\alpha$ sector goods are more profitable.

Now, an equilibrium where $\rho_{A}=\rho_{B}$ is possible and in this equilibrium there is no impetus for international trade. A more interesting trading equilibrium, where $\rho_{A}>\rho^{*}>\rho_{B}$, is also possible. In this equilibrium, the reputation abundant country "A" specializes in the reputation intensive sector $\alpha$ and country "B" specializes in the $\beta$ sector.

Proposition 6: Assume $(A 1-A 5)$. (a.) If $\rho_{\mathrm{A}}>\rho^{*}>\rho_{\mathrm{B}}$, then country A specializes in $\alpha$ sector goods and country $B$ specializes in $\beta$ sector goods. (b.) If, in addition, $\beta$ sector production in country $A$ is less costly by an amount $\zeta$, where $\zeta<\overline{\mathrm{P}}\left(\alpha, \mathrm{S}\left(\mathrm{L}, \rho_{\mathrm{A}}\right), \rho_{\mathrm{A}}\right)-\overline{\mathrm{P}}\left(\beta,\left(\mathrm{L}, \rho_{\mathrm{B}}\right), \rho_{\mathrm{B}}\right)$ then each country specializes in the sector in which they have a reputational comparative advantage and a technological comparative disadvantage.

The intuition behind proposition 6 is as follows. Consider two countries such as Switzerland and Ireland and suppose that the common conjecture about Swiss quality is higher than the common conjecture about Irish quality. Each country can produce linen, watches and a numeraire good such as potatoes. Suppose that low-quality watches and low-quality linen are equally valuable and equally costly to produce. Although high-quality linen is more valuable than low-quality linen, the value difference is not nearly as great as the price difference between high and low-quality watches. Now high-quality watch production is much more costly than high-quality linen production, therefore, a firm only produces high-quality watches if consumers believe with a sufficiently high probability that the unobservable quality is high. This consumer belief is reputation dependant. Hence, Switzerland (with a sufficiently favorable reputation) produces watches and Ireland (with an unfavorable reputation) produces linen. Because a Swiss firm that produces linen is revealed as low quality, all low-quality Swiss firms produce watches and benefit from the Swiss reputation. Similarly for Irish firms and linen. If for some reason it is less costly, ex-ante, to produce linen in Switzerland and watch production costs are still invariant across countries, then Ireland has a 
technological comparative advantage in watch production. However, if Irish watches are (correctly) expected to be of very low quality, then the higher price received for Irish linen - the reputational comparative advantage - can determine the pattern of trade by overshadowing a small technological comparative disadvantage.

It is also possible that the reputation concerns each sector in each country. For example, Ireland may be conjectured as better in the linen sector and Switzerland as better in the watch sector. Or Switzerland may conjectured as better in both sectors, however, the Swiss reputation may be higher in the watch sector. It is easy to see that the reputational comparative advantage and the pattern of specialization in this case is the same as in Proposition 6. This is stated as a direct corollary of Proposition 3.

Corollary 1: Assume that $(A 1-A 4)$ are satisfied and that sector $\alpha$ and $\beta$ differ only in the country-oforigin quality conjectures. If $\rho_{\mathrm{A}}(\alpha) / \rho_{\mathrm{A}}(\beta)>1>\rho_{\mathrm{B}}(\alpha) / \rho_{\mathrm{B}}(\beta)$, then country A specializes in sector $\alpha$ goods and country $B$ specializes in sector $\beta$ goods.

In a world with many sectors, Corollary 1 suggests that a country might produce both $\alpha$ sector and $\beta$ sector goods. Proposition 6 makes the stronger claim that a country will specialize in only $\alpha$ or $\beta$ sector products. Furthermore, Proposition 6 suggests that observed sector reputations may, at a more primitive level, be driven by country-wide reputations.

It is important to note that Proposition 6 only discusses specialization and not the pattern of trade. In particular, because of the assumed infinite elasticity of substitution between $\alpha$ and $\beta$ sector products, it is possible for each country to consume what they produce and export nothing. In addition there is a continuum of trading equilibrium. Although the pattern of trade is uniquely determined by reputational comparative advantage, the volume of exports and imports varies across the set of trading equilibria. Put another way, as a result of the assumed linearity of preferences, consumers are indifferent in equilibrium between consuming varieties of the imported good or varieties of their own export industry. If trade exists, then it will follow the given patterns of specialization, however, even with complete specialization trade need not exist here. Hence, this section is really more focused on how reputation generates patterns of 
specialization. Finally, given these rather special preferences there are no gains from trade in this section.

That is, welfare is the same in any of the trading equilibrium and also in autarky. The easiest way to modify preferences to ensure the existence of a trading equilibrium and also gains from trade is to assume that consumers are unwilling to consume goods from only one sector. More generally, if the elasticity of substitution is finite, then gains from trade would exist and the volume of trade would be uniquely determined.

\section{Conclusion}

We have established that country-of-origin reputations may be self-fulfilling and may determine the types of goods that a country exports as well as the average quality of those exports. When incomplete information concerning quality exists, firms may attempt to signal high quality. When the signal is noisy it cannot perfectly separate high and low-quality firms and posterior beliefs are, in part, a function of the conjectured correlation between country-of-origin and high-quality provision. We provide a necessary condition for at least three "correct in equilibrium" conjectures to exist. Given two otherwise similar countries, that differ only in their country-of-origin reputation, reputational comparative advantage may outweigh technological comparative in determining the pattern of trade.

When saddled with an unfavorable country-of-origin label a nation can use several policies to improve their reputation. A successful policy affects high- and low-quality firms differently. A properly priced export license or quality stamp allows high-quality firms to fully separate themselves, however, this policy reduces low-quality firm profits and may not raise welfare. Subsidization, on a national level, of research and development or human capital accumulation lowers the cost of high quality without requiring firm specific knowledge or payments and increases welfare. 


\section{Appendix A}

Proof of Lemma 1: Suppose that $\mathrm{P}^{\prime}<\mathrm{u}(\mathrm{Z}, \mathrm{i})$ is the high bid. Then an importer that is not consuming all of the good can consume all of the good by choosing a price $\mathrm{P}^{\prime \prime}>\mathrm{P}^{\prime}$, where $\mathrm{P}^{\prime \prime}$ is arbitrarily close to $\mathrm{P}^{\prime}$. The increased consumption has a first-order effect on utility and the increased price has a second-order effect; therefore, some importer chooses the deviating price. Suppose instead that $\mathrm{P}^{\prime \prime \prime}>\mathrm{u}(\mathrm{Z}, \mathrm{i})$ is the high bid. Then an importer bidding $\mathrm{P}^{\prime \prime \prime}$ could deviate to a price $\mathrm{P}^{\prime \prime \prime \prime} \leq \mathrm{u}(\mathrm{Z}, \mathrm{i})$, which would eradicate a negative surplus and must increase utility; therefore, some importer would choose the deviating price.

Proof of Proposition 1: The proof of Proposition 1 requires two lemmas. Lemma 2 shows that the MLRP of $g(Z \mid S)$ can be extended to $g(Z \mid Q)$. This result allows us to characterize the comparative static

properties of $\overline{\mathrm{P}}(\mathrm{S}, \mathrm{i})$ in Lemma 3. We then combine the results of Lemma 3 with the properties of the cost function to show how $\rho_{\mathrm{i}}$ affects $\theta^{\mathrm{H}}$.

Lemma 2: $L R(Z)=g(Z \mid L) / g(Z \mid H)$, is non-increasing in $Z$;

Proof of Lemma 2: Step 1. The first part of our proof shows that $S\left(H, \rho_{i}\right) \geq S\left(L, \rho_{i}\right)$. To see this, suppose instead that $\mathrm{S}\left(\mathrm{H}, \rho_{\mathrm{i}}\right)<\mathrm{S}\left(\mathrm{L}, \rho_{\mathrm{i}}\right)$. Using $\mathrm{A} 1$, this implies

$$
\mathrm{C}\left(\theta, \mathrm{L}, \mathrm{S}\left(\mathrm{L}, \rho_{\mathrm{i}}\right)\right)-\mathrm{C}\left(\theta, \mathrm{L}, \mathrm{S}\left(\mathrm{H}, \rho_{\mathrm{i}}\right)\right)>\mathrm{C}\left(\theta, \mathrm{H}, \mathrm{S}\left(\mathrm{L}, \rho_{\mathrm{i}}\right)\right)-\mathrm{C}\left(\theta, \mathrm{H}, \mathrm{S}\left(\mathrm{H}, \rho_{\mathrm{i}}\right)\right)
$$

Optimality of $\mathrm{S}\left(\mathrm{H}, \rho_{\mathrm{i}}\right)$ ) for the high-quality firm implies

$$
\int_{Z} u\left(Z, \rho_{i}\right) d G\left(Z \mid S\left(H, \rho_{i}\right)\right)-C\left(\theta, H, S\left(H, \rho_{i}\right)\right) \geq \int_{Z} u\left(Z, \rho_{i}\right) d G\left(Z \mid S\left(L, \rho_{i}\right)\right)-C\left(\theta, H, S\left(L, \rho_{i}\right)\right)
$$

Combining these 2 inequalities yields

$$
\begin{aligned}
& \mathrm{C}\left(\theta, \mathrm{L}, \mathrm{S}\left(\mathrm{L}, \rho_{\mathrm{i}}\right)\right)-\mathrm{C}\left(\theta, \mathrm{L}, \mathrm{S}\left(\mathrm{H}, \rho_{\mathrm{i}}\right)\right)>\mathrm{C}\left(\theta, \mathrm{H}, \mathrm{S}\left(\mathrm{L}, \rho_{\mathrm{i}}\right)\right)-\mathrm{C}\left(\theta, \mathrm{H}, \mathrm{S}\left(\mathrm{H}, \rho_{\mathrm{i}}\right)\right) \geq \\
& \int_{Z} \mathrm{u}\left(\mathrm{Z}, \rho_{\mathrm{i}}\right) \mathrm{dG}\left(\mathrm{Z} \mid \mathrm{S}\left(\mathrm{L}, \rho_{\mathrm{i}}\right)\right)-\int_{\mathrm{Z}} \mathrm{u}\left(\mathrm{Z}, \rho_{\mathrm{i}}\right) \mathrm{dG}\left(\mathrm{Z} \mid \mathrm{S}\left(\mathrm{H}, \rho_{\mathrm{i}}\right)\right), \text { which implies } \\
& \int_{Z} \mathrm{u}\left(\mathrm{Z}, \rho_{\mathrm{i}}\right) \mathrm{dG}\left(\mathrm{Z} \mid \mathrm{S}\left(\mathrm{H}, \rho_{\mathrm{i}}\right)\right)-\mathrm{C}\left(\theta, \mathrm{L}, \mathrm{S}\left(\mathrm{H}, \rho_{\mathrm{i}}\right)\right)>\int_{Z} \mathrm{u}\left(\mathrm{Z}, \rho_{\mathrm{i}}\right) \mathrm{dG}\left(\mathrm{Z} \mid \mathrm{S}\left(\mathrm{L}, \rho_{\mathrm{i}}\right)\right)-\mathrm{C}\left(\theta, \mathrm{L}, \mathrm{S}\left(\mathrm{L}, \rho_{\mathrm{i}}\right)\right),
\end{aligned}
$$

which contradicts optimality of $\mathrm{S}\left(\mathrm{L}, \rho_{\mathrm{i}}\right)$ for the low-quality firm. 
Step 2. Now, using the established fact that $S\left(H, \rho_{i}\right) \geq S\left(L, \rho_{i}\right)$, along with the MLRP of $g(Z \mid S)$, we have that, in the terminology of Milgrom (1981), $\mathrm{H}$ is a more favorable signal for $\mathrm{Z}$ than is $\mathrm{L}$. Then by Proposition 1 in Milgrom (1981, p.383), the likelihood ratio of $Z$ given $Q, L R(Z)=g(Z \mid L) / g(Z \mid H)$, is non-increasing in $Z$. It additionally follows that $G(Z \mid H)$ first order stochastically dominates $G(Z \mid L)$ or $\mathrm{G}(\mathrm{Z} \mid \mathrm{H}) \leq \mathrm{G}(\mathrm{Z} \mid \mathrm{L})$

Lemma 3: (a.) $\bar{P}(S, i)$ is non-decreasing in $S$ and satisfies $\partial \bar{P}(S, \cdot) / \partial \rho_{i}>0$.

(b.) $\lim _{\rho \rightarrow 0} \partial^{2} \bar{P}(\cdot, \cdot) / \partial S \partial \rho_{i}>0 . \lim _{\rho \rightarrow 1} \partial^{2} \bar{P}(\cdot, \cdot) / \partial S \partial \rho_{i}<0$

Proof of Lemma 3: (a.) First: $\frac{\partial b(\cdot, i)}{\partial Z}=\frac{-1 \frac{\partial L R(\cdot)}{\partial Z} \frac{1-\rho_{i}}{\rho_{i}}}{\left[1+L R(Z) \frac{1-\rho_{i}}{\rho_{i}}\right]^{2}} \geq 0 ; \frac{\partial b(Z, \cdot)}{\partial \rho_{i}}=\frac{\frac{L R(Z)}{\left(\rho_{i}\right)^{2}}}{\left[1+L R(Z) \frac{1-\rho_{i}}{\rho_{i}}\right]^{2}}>0$.

By A3 we then have: $\partial \mathrm{u}(\mathrm{Z}, \cdot) / \partial \rho_{\mathrm{i}}=\partial \mathrm{b}(\mathrm{Z}, \cdot) / \partial \rho_{\mathrm{i}}[\mathrm{v}(\mathrm{H}, \mathrm{Z})-\mathrm{v}(\mathrm{L}, \mathrm{Z})]>0$; and

$\partial \mathrm{u}\left(\cdot, \rho_{\mathrm{i}}\right) / \partial \mathrm{Z}=\partial \mathrm{b}\left(\cdot, \rho_{\mathrm{i}}\right) / \partial \mathrm{Z}[\mathrm{v}(\mathrm{H}, \mathrm{Z})-\mathrm{v}(\mathrm{L}, \mathrm{Z})] \geq 0$.

Part (a.) then follows from the above comparative statics, the FOSD of G(Z|S) and Theorem 2 of Athey (1998, p.15).

(b.) $\frac{\partial^{2} b(\cdot,)}{\partial \rho_{i} \partial Z}=\frac{\frac{\partial L R(Z)}{\partial Z} \frac{1}{\left(\rho_{i}\right)^{2}}\left[1-\operatorname{LR}(Z) \frac{1-\rho_{i}}{\rho_{i}}\right]}{\left[1+\operatorname{LR}(Z) \frac{1-\rho_{i}}{\rho_{i}}\right]^{3}}$

Taking limits yields: $\lim _{\rho \rightarrow 1} \frac{\partial^{2} \mathrm{~b}(\cdot,)}{\partial \rho_{\mathrm{i}} \partial \mathrm{Z}}<0 ; \quad \lim _{\rho \rightarrow 0} \frac{\partial^{2} \mathrm{~b}(\cdot,)}{\partial \rho_{\mathrm{i}} \partial \mathrm{Z}}>0$.

Now, $\partial^{2} \mathrm{u}(\cdot, \cdot) / \partial \mathrm{Z} \partial \rho_{\mathrm{i}}=\partial^{2} \mathrm{~b}(\cdot, \cdot) / \partial \mathrm{Z} \partial \rho_{\mathrm{i}}[\mathrm{v}(\mathrm{H}, \mathrm{Z})-\mathrm{v}(\mathrm{L}, \mathrm{Z})]$.

Taking limits yields: $\lim _{\rho \rightarrow 0} \partial^{2} u(\cdot, \cdot) / \partial Z \partial \rho_{i} \geq 0$ and $\lim _{\rho \rightarrow 1} \partial^{2} u(\cdot, \cdot) / \partial Z \partial \rho_{i}<0$.

The FOSD of $\mathrm{G}(\mathrm{Z} \mid \mathrm{S})$, Theorem 2 of Athey $(1998, \mathrm{p} .15)$ and the fact that $\partial^{2} \mathrm{C}(\theta, \mathrm{Q}, \cdot) / \partial \mathrm{S} \partial \rho_{\mathrm{i}}=0$ implies that sign $\partial^{2} \mathrm{u}(\cdot, \cdot) / \partial \mathrm{Z} \partial \rho_{\mathrm{i}}=\operatorname{sign} \partial^{2} \checkmark(\cdot, \cdot) / \partial \mathrm{S} \partial \rho_{\mathrm{i}}=\operatorname{sign} \partial^{2} \mathrm{E} \Pi(\theta, \mathrm{Q}, \cdot, \cdot) / \partial \mathrm{S} \partial \rho_{\mathrm{i} \cdot}$

Note from Lemma 3 and $\mathrm{A} 1$ that $\mathrm{E} \Pi\left(\theta, \mathrm{Q}, \mathrm{S}, \rho_{\mathrm{i}}\right)$ is supermodular in $\{-\theta, \mathrm{Q}, \mathrm{S}\}$. Furthermore, from Lemma 3 there exists a $\rho_{0}$ and a $\rho_{1}$ that are sufficiently close to 0 and 1 and that satisfy the following property. For $\rho_{i} \leq \rho_{0}, E \Pi\left(\theta, Q, S, \rho_{i}\right)$ has increasing differences in $\left\{S, \rho_{i}\right\}$, and for $\rho_{i}>\rho_{1}, E \Pi\left(\theta, Q, S, \rho_{i}\right)$ 
has increasing differences in $\left\{-\mathrm{S}, \rho_{\mathrm{i}}\right\}$. Then by Theorem 5 of Milgrom and Shannon (1994, p.164), for $\rho_{\mathrm{i}} \leq \rho_{0},\{\mathrm{Q}, \mathrm{S}\}=\operatorname{argmax}_{\{\mathrm{Q}, \mathrm{S}\}} \mathrm{E} \Pi\left(\theta, \mathrm{Q}, \mathrm{S}, \rho_{\mathrm{i}}\right)$ are nondecreasing in $\rho_{\mathrm{i}}$. For $\rho_{\mathrm{i}}>\rho_{1},\{\mathrm{Q}, \mathrm{S}\}=$ $\operatorname{argmax}_{\{\mathrm{Q}, \mathrm{S}\}} \mathrm{E}\left(\theta, \mathrm{Q}, \mathrm{S}, \rho_{\mathrm{i}}\right)$ are nonincreasing in $\rho_{\mathrm{i}}$.

Proof of Proposition 2: In Figure 2 we note that the intersection with the $45^{\circ}$ line indicates where $\rho_{\mathrm{i}}=$ $\mathrm{F}\left(\theta^{\mathrm{H}}\left(\rho_{\mathrm{i}}\right)\right)$. By (A4) and because the profit function is continuous in $\rho_{\mathrm{i}}, \mathrm{F}\left(\theta^{\mathrm{H}}\left(\rho_{\mathrm{i}}\right)\right)$ crosses the $45^{\circ}$ line from below at some $\rho_{\mathrm{i}}>0$, which ensures the existence of an equilibrium with some firms choosing high quality. Because the measure of firms choosing high quality is bounded below by zero, there must be another equilibrium with fewer firms choosing high quality, which may correspond to $\rho_{i}=0$. Because $\mathrm{F}\left(\theta^{\mathrm{H}}\left(\rho_{\mathrm{i}}\right)\right)>\rho_{\mathrm{i}}$ for some $\rho_{\mathrm{i}}$ there is a third equilibrium with more firms choosing high quality. To see this, note that $\mathrm{F}\left(\theta^{\mathrm{H}}\right)$ is bounded above by 1 . Furthermore, from Proposition 1 we know that $\rho_{\mathrm{i}}=1=\mathrm{F}\left(\theta^{\mathrm{H}}(1)\right)$ is not an equilibrium, therefore, $\theta^{\mathrm{H}}(1)<\bar{\theta}$. Hence, $\mathrm{F}\left(\theta^{\mathrm{H}}\left(\rho_{\mathrm{i}}\right)\right)$ lies below the $45^{\circ}$ line at $\rho_{\mathrm{i}}=1$. Because $\mathrm{F}\left(\theta^{\mathrm{H}}\left(\rho_{\mathrm{i}}\right)\right)$ lies above the $45^{\circ}$ line at some $\rho_{\mathrm{i}}$, it must cross the $45^{\circ}$ line at a third equilibrium. If $\mathrm{F}\left(\theta^{\mathrm{H}}\left(\rho_{\mathrm{i}}\right)\right)$ crosses the $45^{\circ}$ line for a fourth equilibrium, the upper bound on $\mathrm{F}\left(\theta^{\mathrm{H}}\right)$ ensures that it would then cross it for a fifth equilibrium. Hence, generically an odd number of equilibria exist. Because there are no restrictions on the curvature of $\mathrm{F}\left(\theta^{\mathrm{H}}\left(\rho_{\mathrm{i}}\right)\right)$, it may coincide with the $45^{\circ}$ line producing a continuum of equilibrium; however, this case exists with zero probability.

Proof of Proposition 3: First, note that the importer is indifferent (in the interim case) about the particular equilibria selected - their expected utility is $\mathrm{Y}$ in any equilibrium. Second, note that for any two equilibria where $\rho_{\mathrm{i}}^{\prime}>\rho_{\mathrm{i}}$ :

$$
\begin{aligned}
& \operatorname{E\Pi (}\left(\theta^{\mathrm{H}}\left(\rho_{\mathrm{i}}\right), \mathrm{H}, \mathrm{S}\left(\mathrm{H}, \rho_{\mathrm{i}}{ }^{\prime}\right), \rho_{\mathrm{i}}{ }^{\prime}\right)>\operatorname{E} \Pi\left(\theta^{\mathrm{H}}\left(\rho_{\mathrm{i}}{ }^{\prime}\right), \mathrm{H}, \mathrm{S}\left(\mathrm{H}, \rho_{\mathrm{i}}{ }^{\prime}\right), \rho_{\mathrm{i}}{ }^{\prime}\right)=\mathrm{E} \Pi\left(\theta, \mathrm{L}, \mathrm{S}\left(\mathrm{L}, \rho_{\mathrm{i}}{ }^{\prime}\right), \rho_{\mathrm{i}}{ }^{\prime}\right)> \\
& \operatorname{E\Pi }\left(\theta, \mathrm{L}, \mathrm{S}\left(\mathrm{L}, \rho_{\mathrm{i}}\right), \rho_{\mathrm{i}}{ }^{\prime}\right)>\operatorname{E} \Pi\left(\theta, \mathrm{L}, \mathrm{S}\left(\mathrm{L}, \rho_{\mathrm{i}}\right), \rho_{\mathrm{i}}\right)=\mathrm{E} \Pi\left(\theta^{\mathrm{H}}\left(\rho_{\mathrm{i}}\right), \mathrm{H}, \mathrm{S}\left(\mathrm{H}, \rho_{\mathrm{i}}\right), \rho_{\mathrm{i}}\right) .
\end{aligned}
$$

The first inequality is due to A1. The two equalities use the definition of $\theta^{\mathrm{H}}$. The second inequality is a result of firm maximization and the third inequality is a result of Lemma $3 \mathrm{a}$. 
Proof of Proposition 4: a) Rewriting equation 2 and remembering that $\mathrm{I}(\theta, \mathrm{L})=0$ we have:

$\left[\overline{\mathrm{P}}\left(\mathrm{S}\left(\mathrm{H}, \rho_{\mathrm{i}}\right), \rho_{\mathrm{i}}\right)-\mathrm{c}\left(\mathrm{H}, \mathrm{S}\left(\mathrm{H}, \rho_{\mathrm{i}}\right)\right)\right]-\left[\overline{\mathrm{P}}\left(\mathrm{S}\left(\mathrm{L}, \rho_{\mathrm{i}}\right), \rho_{\mathrm{i}}\right)-\mathrm{c}\left(\mathrm{L}, \mathrm{S}\left(\mathrm{L}, \rho_{\mathrm{i}}\right)\right)\right]=\mathrm{I}\left(\theta^{\mathrm{H}}, \mathrm{H}\right)>\mathrm{I}\left(\theta^{\mathrm{H}}, \mathrm{H}\right)-\sigma_{j}^{\mathrm{K}}$ After the subsidy, if $\theta^{\mathrm{H}}$ is not less than or equal to $\underline{\theta}$ (so that $\rho_{\mathrm{i}}=0$ is not an equilibrium), then $\theta^{\mathrm{H}}$ is not the marginal firm, since higher-cost firms produce high quality. Denote $\theta^{\mathrm{H}^{\prime}}$ as the marginal firm after the subsidy but with the pre-subsidy conjecture. Because $\theta^{\mathrm{H}^{\prime}}>\theta^{\mathrm{H}}$, it is immediate that $\mathrm{F}\left(\theta^{\mathrm{H}}\right)<\mathrm{F}\left(\theta^{\mathrm{H}^{\prime}}\right)$ so that the pre-policy conjecture is correct in the post-subsidy equilibrium with probability 0 . Now $\partial \mathrm{F}\left(\theta^{\mathrm{H}}(\cdot) / \partial \rho_{\mathrm{i}}\right.$ $<1$ in a stable equilibrium; therefore, $\rho_{\mathrm{i}}$ must increase to restore equilibrium. Hence when starting from a stable equilibrium $\theta^{\mathrm{H}^{\prime}}>\theta^{\mathrm{H} \sigma}>\theta^{\mathrm{H}}$. When starting from an unstable equilibrium determination of the new equilibrium is dependent on the specification of the adjustment process. The cost of providing $\sigma_{j}^{K}$ to all of the firms that choose high quality is $\mathrm{F}\left(\theta^{\mathrm{H \sigma}}\right) \sigma_{\mathrm{j}}^{\mathrm{K}}=\sigma^{\mathrm{K}}$. The expected welfare gain from the subsidy is:

$$
\begin{aligned}
& \mathrm{W}^{\mathrm{i}}\left(\sigma^{\mathrm{K}}\right)-\mathrm{W}^{\mathrm{i}}(0) \\
& =\int_{\underline{\theta}}^{\theta^{\mathrm{H} \sigma}}\left(\mathrm{E} \Pi\left[\theta, \mathrm{H}, \mathrm{S}\left(\mathrm{H}, \rho_{\mathrm{i}}\right), \mathrm{F}\left(\theta^{\mathrm{H} \sigma}\right)\right]+\sigma_{\mathrm{j}}^{\mathrm{K}}\right) \mathrm{dF}(\theta)+\int_{\theta^{\mathrm{H} \sigma}}^{\bar{\theta}} \mathrm{E} \Pi\left[\theta, \mathrm{L}, \mathrm{S}\left(\mathrm{L}, \rho_{\mathrm{i}}\right), \mathrm{F}\left(\theta^{\mathrm{HK}}\right)\right] \mathrm{dF}(\theta) \\
& -\mathrm{F}\left(\theta^{\mathrm{H} \sigma}\right) \sigma_{\mathrm{j}}^{\mathrm{K}}-\int_{\underline{\theta}}^{\theta^{\mathrm{H}}} \mathrm{E} \Pi\left[\theta, \mathrm{H}, \mathrm{S}\left(\mathrm{H}, \rho_{\mathrm{i}}\right), \mathrm{F}\left(\theta^{\mathrm{H}}\right)\right] \mathrm{dF}(\theta)+\int_{\theta^{\mathrm{H}}}^{\bar{\theta}} \mathrm{E} \Pi\left[\theta, \mathrm{L}, \mathrm{S}\left(\mathrm{L}, \rho_{\mathrm{i}}\right), \mathrm{F}\left(\theta^{\mathrm{H}}\right)\right] \mathrm{dF}(\theta) \\
& =\int_{\underline{\theta}}^{\theta^{\mathrm{H} \sigma}} \quad \mathrm{E} \Pi\left[\theta, \mathrm{H}, \mathrm{S}\left(\mathrm{H}, \rho_{\mathrm{i}}\right), \mathrm{F}\left(\theta^{\mathrm{H \sigma}}\right)\right] \mathrm{dF}(\theta)+\left[1-\mathrm{F}\left(\theta^{\mathrm{H} \sigma}\right)\right] \cdot \mathrm{E} \Pi\left[\theta, \mathrm{L}, \mathrm{S}\left(\mathrm{L}, \rho_{\mathrm{i}}\right), \mathrm{F}\left(\theta^{\mathrm{H} \sigma}\right)\right] \\
& -\int_{\underline{\theta}}^{\theta^{\mathrm{H}}} \mathrm{E} \Pi\left[\theta, \mathrm{H}, \mathrm{S}\left(\mathrm{H}, \rho_{\mathrm{i}}\right), \mathrm{F}\left(\theta^{\mathrm{H}}\right)\right] \mathrm{dF}(\theta)-\left[1-\mathrm{F}\left(\theta^{\mathrm{H}}\right)\right] \cdot \mathrm{E} \Pi\left[\theta, \mathrm{L}, \mathrm{S}\left(\mathrm{L}, \rho_{\mathrm{i}}\right), \mathrm{F}\left(\theta^{\mathrm{H}}\right)\right] \\
& =\int_{\underline{\theta}}^{\theta^{\mathrm{H}}}\left\{\mathrm{E} \Pi\left[\theta, \mathrm{H}, \mathrm{S}\left(\mathrm{H}, \rho_{\mathrm{i}}\right), \mathrm{F}\left(\theta^{\mathrm{H} \sigma}\right)\right]-\mathrm{E} \Pi\left[\theta, \mathrm{H}, \mathrm{S}\left(\mathrm{H}, \rho_{\mathrm{i}}\right), \mathrm{F}\left(\theta^{\mathrm{H}}\right)\right]\right\} \mathrm{dF}(\theta) \\
& +\left[1-\mathrm{F}\left(\theta^{\mathrm{H}}\right)\right] \cdot\left\{\mathrm{E} \Pi\left[\theta, \mathrm{L}, \mathrm{S}\left(\mathrm{L}, \rho_{\mathrm{i}}\right), \mathrm{F}\left(\theta^{\mathrm{H} \sigma}\right)\right]-\mathrm{E} \Pi\left[\theta, \mathrm{L}, \mathrm{S}\left(\mathrm{L}, \rho_{\mathrm{i}}\right), \mathrm{F}\left(\theta^{\mathrm{H}}\right)\right]\right\} \\
& \left.+\int_{\theta^{\mathrm{H}}}^{\theta^{\mathrm{H} \sigma}}\left\{\mathrm{E} \Pi\left[\theta, \mathrm{H}, \mathrm{S}\left(\mathrm{H}, \rho_{\mathrm{i}}\right), \mathrm{F}\left(\theta^{\mathrm{H} \sigma}\right)\right]-\mathrm{E} \Pi\left[\theta, \mathrm{L}, \mathrm{S}\left(\mathrm{L}, \rho_{\mathrm{i}}\right), \mathrm{F}\left(\theta^{\mathrm{H} \sigma}\right)\right]\right) \mathrm{dF}(\theta)\right\}>0 .
\end{aligned}
$$

By Proposition 3 the first two bracketed terms in the inequality are positive. The third bracketed term is positive by the definition of the marginal firm for an equilibrium conjecture of $\mathrm{F}\left(\theta^{\mathrm{H \sigma}}\right)$. 


\section{Dominance Refinement}

The dominance refinement can be formalized in the following way. If the observable policy response is denoted by $\tau$, then, after observing the firm taking an action $\tau$, the posterior belief can be represented as $\operatorname{Pr}[Q(\theta, i) \mid \tau, Z$, i]. Given this posterior belief the consumers takes an action $P$, which is the offered price. Define the set of non-dominated policy responses as follows:

$$
\xi(\tau)=\left\{\mathrm{Q}(\theta, \mathrm{i}) \mid \sim \exists \tau^{\prime} \text { satisfying } \operatorname{Min}_{\mathrm{P}^{\prime}} \mathrm{E} \Pi\left(\theta, \mathrm{Q}, \mathrm{S}, \tau^{\prime}, \rho_{\mathrm{i}}\right)>\operatorname{Max}_{\mathrm{P}} \mathrm{E} \Pi\left(\theta, \mathrm{Q}, \mathrm{S}, \tau, \rho_{\mathrm{i}}\right)\right\}
$$

Then the dominance refinement can be written as follows:

$$
\operatorname{Pr}\left[\mathrm{Q}(\theta, \mathrm{i}) \mid \tau^{\prime \prime}, \mathrm{Z}, \mathrm{i}\right]>0 \text { if and only if } \tau^{\prime \prime} \in \xi(\tau) . \quad \text { (E2-Dominance) }
$$

\section{Proof of Proposition 5:}

Under the most optimistic beliefs, $\operatorname{Pr}(\mathrm{H} \mid \mathrm{Stamp})=1-\operatorname{Pr}(\mathrm{H} \mid$ No Stamp $)=1$. A high-quality firm (who plans on receiving the rebate) chooses between expected revenue of $\mathrm{P}(\mathrm{S}(\mathrm{L}, 1), 1)-\tau^{\mathrm{R}}+\tau^{\mathrm{R}}=$ $\overline{\mathrm{P}}(\mathrm{S}(\mathrm{L}, 1), 1)>\overline{\mathrm{P}}(\mathrm{S}(\mathrm{L}, 0), 0)$. Hence, for these beliefs all high-quality firms purchase the stamp. A lowquality firm purchasing the stamp has expected revenue of $\mathrm{P}(\mathrm{S}(\mathrm{L}, 1), 1)-\tau^{\mathrm{R}}=\overline{\mathrm{P}}(\mathrm{S}(\mathrm{L}, 1), 1)-$ $\overline{\mathrm{P}}(\mathrm{S}(\mathrm{L}, 1), 1)+\overline{\mathrm{P}}(\mathrm{S}(\mathrm{L}, 0), 0)-\mathrm{k}<\overline{\mathrm{P}}(\mathrm{S}(\mathrm{L}, 0), 0)$. Hence, no low-quality firms purchase the stamp. We now show that these are the only equilibrium beliefs. First, suppose that some consumer believes $\operatorname{Pr}(\mathrm{H} \mid$ No Stamp $) \in(0,1)$. In this case, the expected revenue is still less than $\overline{\mathrm{P}}(\mathrm{S}(\mathrm{H}, 1), 1)$, and, as shown above, only high-quality firm prefer to purchase the stamp, therefore, this belief cannot be correct in equilibrium. Second, suppose that some consumer believes that $\operatorname{Pr}(\mathrm{H} \mid \operatorname{No} \mathrm{Stamp})=1$, then no firm purchases the stamp. This belief can only be correct in the non-generic case where all firms produce high quality. Finally, suppose some consumer believes that $\operatorname{Pr}(\mathrm{H} \mid \mathrm{Stamp})<1$. However, under no belief does a low-quality firm purchase the stamp, so this belief does not satisfy E2-Dominance.

\section{Proof of Proposition 6:}

We first demonstrate a single crossing property between sectors and conjectures.

$\operatorname{Lemma~4:~} \partial E \Pi(\theta, \alpha, Q, S, \cdot) / \partial \rho_{i}>\partial E \Pi(\theta, \beta, Q, S, \cdot) / \partial \rho_{i}$ 
Proof of Lemma 4: From A5 and Lemma 3a, we have:

$$
\partial \mathrm{u}(\alpha, \mathrm{Z}, \cdot) / \partial \rho_{\mathrm{i}}=\partial \mathrm{b}(\mathrm{Z}, \cdot) / \partial \rho_{\mathrm{i}}[\mathrm{v}(\alpha, \mathrm{H})-\mathrm{v}(\alpha, \mathrm{L})]>\partial \mathrm{b}(\mathrm{z}, \cdot) / \partial \rho_{\mathrm{i}}[\mathrm{v}(\beta, \mathrm{H})-\mathrm{v}(\beta, \mathrm{L})]=\partial \mathrm{u}(\beta, \mathrm{Z}, \cdot) / \partial \rho_{\mathrm{i}}
$$

By the FOSD of G(Z|Q) and Theorem 2 of Athey (1998, p.15), we then have:

$\partial \overline{\mathrm{P}}(\alpha, \mathrm{S}, \cdot) / \partial \rho_{\mathrm{i}}>\partial \overline{\mathrm{P}}(\beta, \mathrm{S}, \cdot) / \partial \rho_{\mathrm{i}} \cdot$

Because $\partial \mathrm{C}(\theta, \alpha, \mathrm{Q}, \mathrm{S}) / \partial \rho_{\mathrm{i}}=\partial \mathrm{C}(\theta, \beta, \mathrm{Q}, \mathrm{S}) / \partial \rho_{\mathrm{i}}=0$, the Lemma follows immediately.

(a.) By Lemma 4, the definition of $\rho^{*}$, and proposition 3, if $\rho_{A}>\rho^{*}>\rho_{B}$, then

$\mathrm{E} \Pi\left(\theta, \alpha, \mathrm{H}, \mathrm{S}\left(\mathrm{H}, \rho_{\mathrm{A}}\right), \rho_{\mathrm{A}}\right)>\mathrm{E} \Pi\left(\theta, \beta, \mathrm{H}, \mathrm{S}\left(\mathrm{H}, \rho_{\mathrm{A}}\right), \rho_{\mathrm{A}}\right)>\mathrm{E} \Pi\left(\theta, \alpha, \mathrm{H}, \mathrm{S}\left(\mathrm{H}, \rho^{*}\right), \rho^{*}\right)=$

$\mathrm{E} \Pi\left(\theta, \beta, H, S\left(H, \rho^{*}\right), \rho^{*}\right)>\operatorname{E} \Pi\left(\theta, \beta, H, S\left(H, \rho_{B}\right), \rho_{B}\right)>\operatorname{E} \Pi\left(\theta, \alpha, H, S\left(H, \rho_{B}\right), \rho_{B}\right)$.

Hence, high-quality country A firms choose sector $\alpha$ and high-quality country B firms choose sector $\beta$. A country A firm in sector $\beta$, therefore, generates posterior beliefs of $\operatorname{Pr}(\mathrm{H} \mid \beta, \mathrm{A})=0$. Now, by assumption, we have $\mathrm{C}\left(\theta, \alpha, \mathrm{L}, \mathrm{S}\left(\mathrm{L}, \rho^{\prime}\right)\right)=\mathrm{C}\left(\theta, \beta, \mathrm{L}, \mathrm{S}\left(\mathrm{L}, \rho^{\prime}\right)\right)$ for all $\rho^{\prime}$, therefore, it follows that:

$$
\mathrm{E} \Pi\left(\theta, \alpha, \mathrm{L}, \mathrm{S}\left(\mathrm{L}, \rho_{\mathrm{A}}\right), \rho_{\mathrm{A}}\right)>\mathrm{E} \Pi(\theta, \alpha, \mathrm{L}, \mathrm{S}(\mathrm{L}, 0), 0)=\mathrm{E} \Pi(\theta, \beta, \mathrm{L}, \mathrm{S}(\mathrm{L}, 0), 0) .
$$

Therefore, all country A firms choose sector $\alpha$. Likewise, upon seeing a country B firm in sector $\alpha$, the posterior beliefs must be $\operatorname{Pr}(\mathrm{H} \mid \alpha, \mathrm{B})=0$. By the above argument, it is then true that

$$
\mathrm{E} \Pi\left(\theta, \beta, \mathrm{L}, \mathrm{S}\left(\mathrm{L}, \rho_{\mathrm{B}}\right), \rho_{\mathrm{B}}\right)>\mathrm{E} \Pi(\theta, \beta, \mathrm{L}, \mathrm{S}(\mathrm{L}, 0), 0)=\mathrm{E} \Pi(\theta, \alpha, \mathrm{L}, \mathrm{S}(\mathrm{L}, 0), 0) .
$$

so that all country B firms choose sector $\beta$.

(b.) If country A production in the $\beta$ sector is cheaper by an amount $\zeta$, then the country B has a

technological comparative in sector $\alpha$. Because the production cost is lower by $\zeta$ for either quality, the technological comparative advantage does not affect beliefs and, because it is sufficiently small, it cannot overcome the reputational comparative advantage.

Proof of Corollary 1: If $\rho_{A}(\alpha) / \rho_{A}(\beta)>1>\rho_{B}(\alpha) / \rho_{B}(\beta)$, then by Proposition 3 sector $\alpha$ products are more profitable in country " $\mathrm{A}$ " and sector $\beta$ are more profitable in country "B". Profit maximization by firms yields the hypothesized pattern of specialization. 


\section{Appendix B}

(This appendix is made available for the referees, but is not part of the submitted paper. It will be made available, upon request, for interested readers.)

The existence of multiple equilibrium that can be ranked by $\rho_{\mathrm{i}}$ does not depend on the inability of price to signal quality. If price is the only signal and high-quality production has a higher cost the same result is obtained. First, assume that $\mathrm{P}$ is perfectly observed. Let $\mathrm{I}(\theta, \mathrm{Q})$ be defined as before but assume that quality is chosen for both periods of a two-period game. Let low quality be worthless so that, under full information, $v(L)=0=I(\theta, L)$. Then a first period $\mathrm{P}_{1}<0$ will eradicate low quality. All $\theta \leq \theta^{\mathrm{H}}$, where $\theta^{\mathrm{H}}$ is defined by $(1+\delta) \cdot \mathrm{I}\left(\theta^{\mathrm{H}}, \mathrm{H}\right)=\mathrm{P}_{1}+\delta \cdot \mathrm{v}(\mathrm{H})$, will choose high quality. If price is noisy because of, say, an unanticipated exchange rate shock, then the importer only observes $\mathrm{P}_{1}+\varepsilon$. If the above assumptions on the distribution of $\varepsilon$ are maintained, then the importers' posterior belief will be, in part, a function of their conjecture. A low conjecture reduces the posterior probability that a low price was chosen. Because a lower price signal is needed for the same probability of a high-quality sender, the benefit to choosing high quality is reduced in a country with an unfavorable reputation. As a result $\theta^{\mathrm{H}}$ drops and the reputation, and low conjecture, become self-fulfilling. 


\section{Appendix C: A Specific Factors Model}

(This appendix is made available for the referees, but is not part of the submitted paper.

$$
\text { It will be made available, upon request, for interested readers.) }
$$

The $\eta_{i}$ identical agents in country i can sell their one endowed unit of labor to one of the $\mathrm{N}_{\mathrm{i}}$ manufacturing firms $\left(j \in 1, \ldots, N_{i}\right)$ or to the numeraire sector in country $i$. The $\mathrm{N}_{\mathrm{i}}$ manufacturing firms in country i are owned by the $\eta_{i}$ agents who use their equal share of the firms' profits as well as their wage income to purchase goods. The numeraire good $\left(\mathrm{X}_{0}\right)$ is produced with a constant-returns-to-scale technology: $X_{0 \mathrm{i}}=\eta_{0 \mathrm{i}}$, where $\eta_{0 \mathrm{i}}$ is the amount of labor used in numeraire production. The numeraire is freely tradable and can be used to rectify trade imbalances. Furthermore, because $\eta_{\mathrm{i}}$ is assumed to be sufficiently large there is positive numeraire production in each country. The wage in each country is, therefore, equal to the price of the numeraire good which is normalized to one. The technology for producing the manufactured goods is as given in the previous section. In particular, with the wage equal to one, $C\left(\theta_{j}, Q_{j}, S_{j}\right)=\eta_{m j i}$ represents the minimum cost function for each firm type. The labor demand by manufacturing firm j in country $i$ is $\eta_{\mathrm{mji}}$ so that the entire manufacturing labor demand in country $i$ is $\eta_{\mathrm{mi}}$.

The resource constraint is, therefore, given as $X_{0 i}+\sum_{j=1}^{N_{i}} C\left(\theta_{j}, Q_{j}, S_{j}\right)=\eta_{0 i}+\eta_{m i} \leq \eta_{i}$.

The manufactured goods are now produced for consumption by the agents in both countries. These "consumers" take the place of the importers in the previous section. The agents' preferences can be represented by the utility function described in A3 and the agents' income is now endogenized as described above, therefore, their identical indirect utility functions can be represented as:

$\mathrm{V}(\mathrm{Z}, \mathrm{P}, \theta, \mathrm{i}, \eta)=\sum_{\mathrm{i}} \sum_{\mathrm{j}} \gamma_{\mathrm{ij}}\left(\mathrm{P}_{\mathrm{ij}}\right) \cdot\left[\mathrm{u}\left(\mathrm{Z}_{\mathrm{j}}, \mathrm{i}\right)-\mathrm{P}\left(\mathrm{Z}_{\mathrm{j}}, \mathrm{i}\right)\right]+\sum_{\mathrm{j}} \mathrm{E \Pi}\left(\theta_{\mathrm{j}}, \mathrm{i}\right) / \eta_{\mathrm{i}}+1=\sum_{\mathrm{j}} \mathrm{E \Pi}\left(\theta_{\mathrm{j}}, \mathrm{i}\right) / \eta_{\mathrm{i}}+1$

Equilibrium for country "i”" is then described by equations (E1 - E3) the above indirect utility function and the resource constraint. 


\section{References}

Armington, P. 1969. “A Theory of Demand for Products Distinguished by Place of Production," IMF Staff Papers, 16: 159-178.

Arrow, K. J. 1974. "The Theory of Discrimination," in O. Ashenfelter and A. Rees, eds., Discrimination in Labor Markets. Princeton, NJ: Princeton University Press.

Athey, S. 1998. "Comparative Statics Under Uncertainty: Single Crossing Properties and LogSupermodularity," Massachusettes Institute of Technology Working Paper No. 96-22R.

Bagwell, K. and B. Staiger. 1989. "The Role of Export Subsidies When Product Quality Is Unknown," Journal of International Economics, 27: 69-89.

Bagwell, K., "Commitment and Observability in Games," Games and Economic Behavior, 1995, 8, pp. 271-280.

Bagwell, K. 1991. "Optimal Export Policy for a New-Product Monopoly," American Economic Review, 81: 1156-1169.

Bilkey, W. and E. Nes. 1982. "Country-of-Origin Effects on Product Evaluations," Journal of International Business Studies, 13: 89-99.

Bodenhausen, G. and R. Wyer. 1985. "Effects of Stereotypes on Decision Making and InformationProcessing Strategies," Journal of Personality and Social Psychology, 48: 267-282.

Bodenhausen, G. and M. Lichtenstein. 1987. "Social Stereotypes and Information-Processing Strategies: The Impact of Task Complexity," Journal of Personality and Social Psychology, 52: 871-880.

Chiang, S. and R. Masson. 1988. "Domestic Industrial Structure and Export Quality," International Economic Review, 29: 261-270.

Chen, M. 1991. "The Role of R\&D Subsidies When Incomplete Information is an Entry Barrier," Journal of International Economics, 31: 251-270.

Coate, S. and G. Loury. 1993. "Will Affirmative Action Policies Eliminate Negative Stereotypes," American Economic Review, 83: 1220-1240.

Grossman, G. and H. Horn. 1988. "Infant-Industry Protection Reconsidered: the Case of Informational Barriers to Entry," The Quarterly Journal of Economics, 103: 767-787.

Han, C. M. and V. Terpstra. 1988. "Country-of-Origin Effects for Uni-National and Bi-National Products," Journal of International Business Studies, 16: 235-255.

Haucap, J., C. Wey and J. Barmbold. 1997 "Location Choice as a Signal for Product Quality: The Economics of "Made in Germany," Journal of Institutional and Theoretical Economics, 153: 510-531.

Head, D. 1993. "Advertising Slogans and the 'Made-in' Concept," International Journal of Advertising, 7: 237-252. 
Holmstrom, B. and R. Myerson. 1983. "Efficient and Durable Decisions Rules with Incomplete Information," Econometrica, 51: 1799-1819.

Lutz, N.A. 1989. "Warranties as Signals Under Consumer Moral Hazard," RAND Journal of Economics, 20: 239-255.

Maggi, G., "The Value of Commitment with Imperfect Observability and Private Information," $\underline{\text { RAND }}$ Journal of Economics, Winter 1999, 30:4, pp.555-574.

Mayer, W. 1984. “The Infant-Export Industry Argument," Canadian Journal of Economics, 17: 249 -269 .

Milgrom, P. 1981. "Good News and Bad News: Representation Theorems and Applications," Bell Journal of Economics, 12: 380-391.

Milgrom, P. and C. Shannon. 1994. "Monotone Comparative Statics," Econometrica, 62: 157-180.

Morawetz, D. 1981. Why the Emperor's New Clothes Are Not Made in Columbia. Oxford: Oxford University Press.

Vernon, R. 1966. "International Investment and International Trade in the Product Cycle," Quarterly Journal of Economics, 80: 190-207.

Wortzel, L. and H. Wortzel. 1979. "Marketing Manufactured Exports from LDCs: Progress and Recommendations for Further Progress," Mimeo, Boston University, School of Management. 


\section{Figure 1}

Timing of Actions and Information Structure

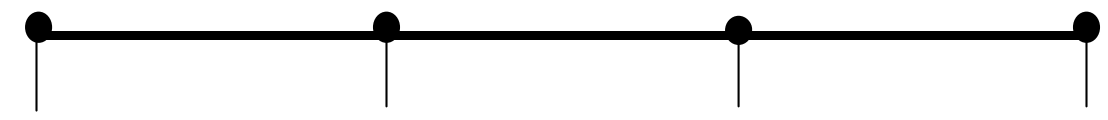

$\begin{array}{llll}\text { Firm receives } & \text { Firm observes } & \text { Importers observe } & \text { Firm sells to } \\ \{\theta, \mathrm{i}\} . & \begin{array}{l}\{\theta, \mathrm{i}\} \text { and } \\ \text { chooses }\{\mathrm{Q}, \mathrm{S}\} .\end{array} & \begin{array}{l}\{\mathrm{i}, \mathrm{Z}\} \text { and each } \\ \text { chooses } \mathrm{P} .\end{array} & \begin{array}{l}\text { highest } \mathrm{P} . \\ \end{array} \\ & & & \text { Payoffs clear. } \\ & & \end{array}$

\section{Figure 2}

$\underline{\text { Multiple Correct Equilibrium Beliefs }}$

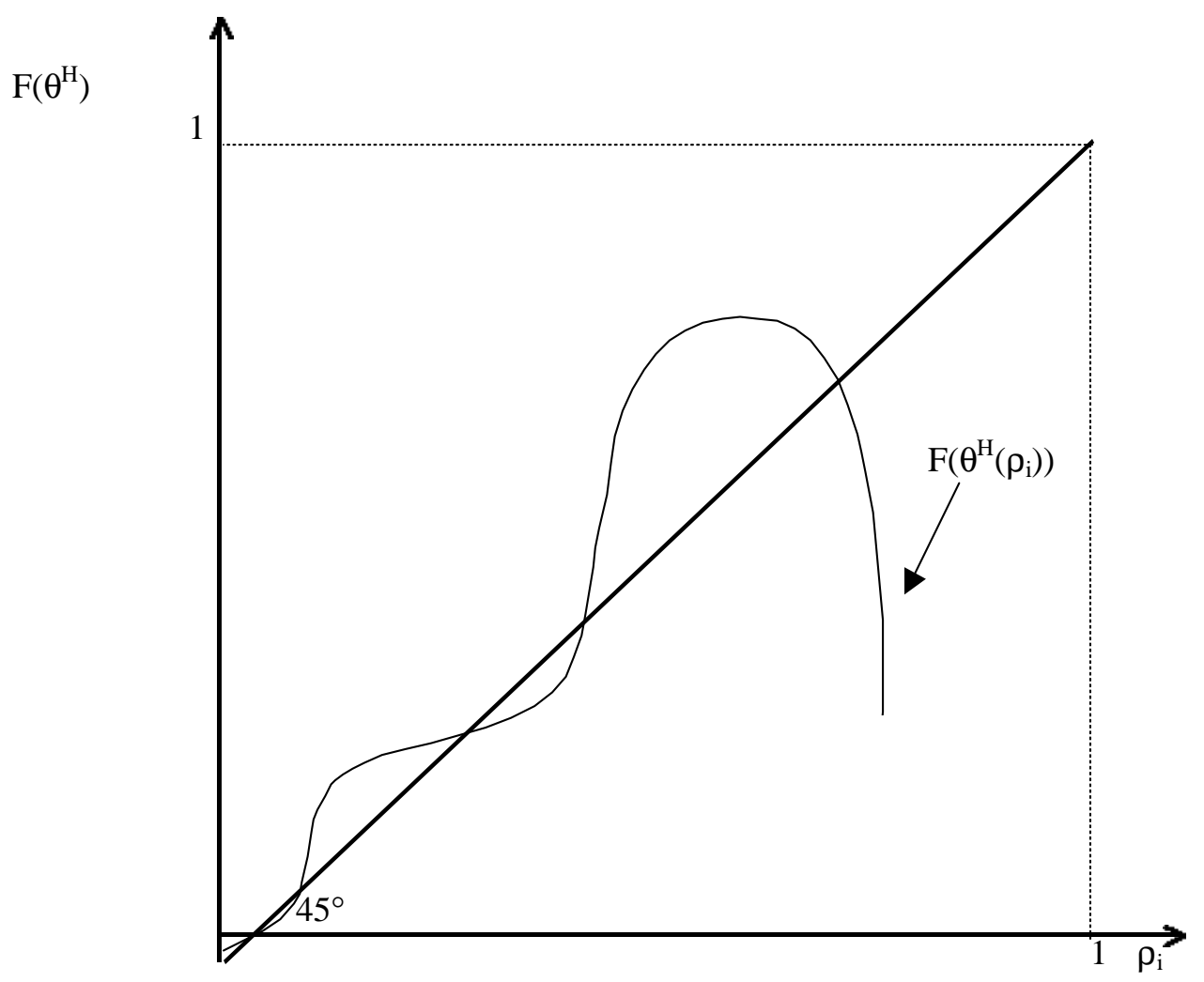


Figure 3

Timing of Actions and Information Structure With Policymaker

\begin{tabular}{|c|c|c|c|c|c|}
\hline $\begin{array}{l}\text { Firm receives } \\
\{\theta, i\} .\end{array}$ & $\begin{array}{l}\text { Policymaker } \\
\text { announces } \\
\text { policy. }\end{array}$ & $\begin{array}{l}\text { Firms observe } \\
\{\theta, \mathrm{i}\} \text { and policy, } \\
\text { and each chooses } \\
\{\mathrm{Q}, \mathrm{S}\} \text { and } \\
\text { response to policy } \\
\text { (if applicable). }\end{array}$ & $\begin{array}{l}\text { Importers observe } \\
\{\mathrm{i}, \mathrm{Z}\} \text {, the policy, } \\
\text { and the response } \\
\text { to policy (if } \\
\text { applicable), and } \\
\text { each chooses } \mathrm{P} \text {. }\end{array}$ & $\begin{array}{l}\text { Firms sell to } \\
\text { highest P. } \\
\text { Markets clear. } \\
\text { Payoffs received. }\end{array}$ & $\begin{array}{l}\text { Policymaker } \\
\text { observes Q and } \\
\text { collects or } \\
\text { issues } \\
\text { payments in } \\
\text { accordance } \\
\text { with policy (if } \\
\text { applicable). }\end{array}$ \\
\hline
\end{tabular}

Figure 4

A Small Subsidy Improving Reputation in All Stable Equilibria and a

$\underline{\text { Large Subsidy Eradicating All Unfavorable Reputations }}$

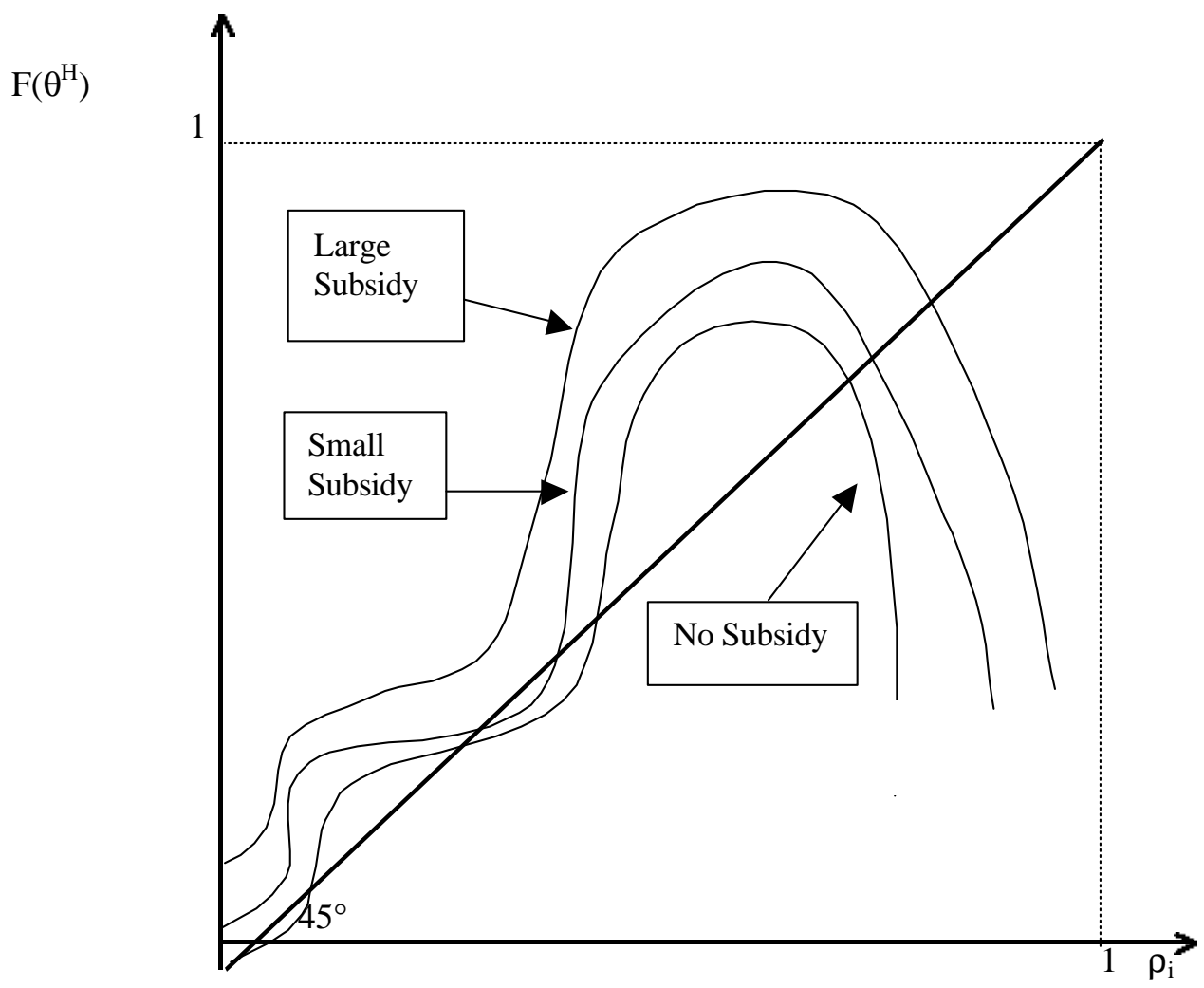

